

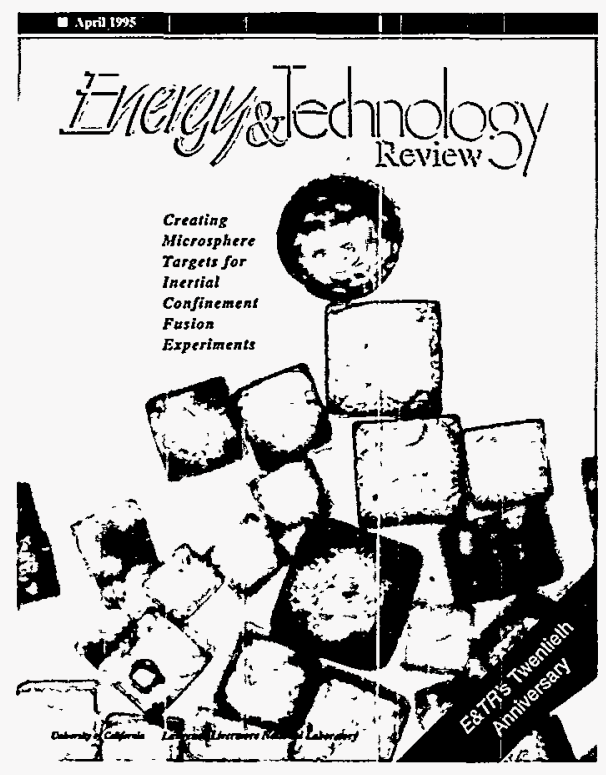

\section{About the Cover}

This 0.5-mm-diameter plasmapolymer-coated capsule is formed around a tiny, hollow microsphere. Shown next to grains of table salt, the capsule holds a gaseous isotope of hydrogen before it is blasted by the energy from the Nova Laser system in inertial confinement fusion experiments at LLNL. Our research to develop the materials for these capsules is evolving to meet the needs of the proposed National Ignition Facility.

Photos: James E. Stoots
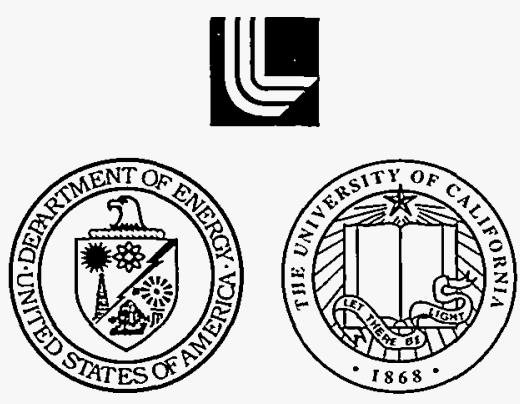

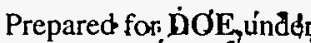
No. W-7405-Eng-48

\section{About the Journal}

The Lawrence Livermore National Laboratory, operated by the University of California for the United States Department of Energy, was established in 1952 to do research on nuclear weapons and magnetic fusion energy. Since then, in response to new national needs, we have added other major programs, including technology transfer, laser science (fusion, isotope separation, materials processing), biology and biotechnology, environmental research and remediation, arms control and nonproliferation, advanced defense technology, and applied energy technology. These programs, in turn, require research in basic scientific disciplines, including chemistry and materials science, computing science and technology, engineering, and physics. The Laboratory also carries out a variety of projects for other federal agencies. Energy and Technology Review is published monthly to report on unclassified work in all our programs. Please address any correspondence concerning Energy and Technology Review (including name and address changes) to Mail Stop L-3, Lawrence Livermore National Laboratory, P.O. Box 808, Livermore, CA 94551, ', 1, , br telephonem (510).422-4859. (You may fax this information to (510) $422-8672$ or send electronic mail to etr-mail@llnl.gov.) 


\section{DISCLAIMER}

This report was prepared as an account of work sponsored by an agency of the United States Government. Neither the United States Government nor any agency thereof, nor any of their employees, make any warranty, express or implied, or assumes any legal liability or responsibility for the accuracy, completeness, or usefulness of any information, apparatus, product, or process disclosed, or represents that its use would not infringe privately owned rights. Reference herein to any specific commercial product, process, or service by trade name, trademark, manufacturer, or otherwise does not necessarily constitute or imply its endorsement, recommendation, or favoring by the United States Government or any agency thereof. The views and opinions of authors expressed herein do not necessarily state or reflect those of the United States Government or any agency thereof. 


\section{DISCLAIMER}

Portions of this document may be illegible in electronic image products. Images are produced from the best available original document. 


\section{April 1995}

SCIENTIFIC EDITOR

William A. Bookless

Publication Editor

Sue Stull

Writers

Kevin Gleason, Dale Sprouse, Dean Wheatcraft

ISSUE COORDinators

Paul Harding, George Kitrinos

Designers

Paul Harding, George Kitrinos

\section{GRAPHIC ARTIST \\ Treva Carey}

Compositor

Louisa Cardoza

Proofreader

Catherine M. Williams

This document was prepared as an account of work sponsored by an agency of the United States Government. Neither the United States Govemment nor the University of California nor any of their employees makes any warranty, expressed or implied, or assumes any legal liability or responsibility for the accuracy, completeness, or usefulness of any information, apparatus, product, or process disclosed, or represents that its use would not infringe privately owned rights. Reference herein to any specific commercial product, process, or service by trade name, trademark, manufacturer, or otherwise does not necessarily constitute or imply its endorsement, recommendation, or favoring by the United States Government or the University of California. The views and opinions of authors expressed herein do not necessarily state or reflect those of the United States Government or the University of California and shall not be used for advertising or product endorsement purposes.

Printed in the United States of America Available from

National Technical Information Service U.S. Department of Commerce 5285 Port Royal Road Springfield, Virginia 22161

UCRL-52000-95-4

Distribution Category UC-700 April 1995

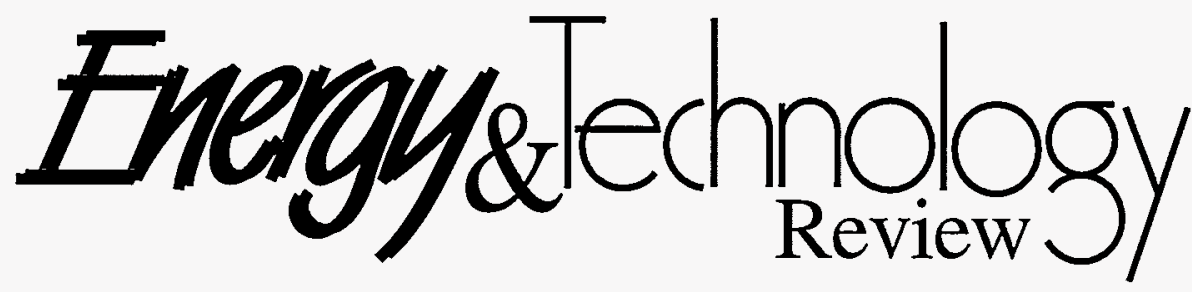

Feature Articles

Creating Microsphere Targets for Inertial Confinement Fusion Experiments

At the heart of inertial confinement fusion (ICF) experiments are tiny, hollow microspheres used as targets. Their size, materials of construction, production methods, and structural characteristics have evolved to meet the demands of doing experiments at the Nova laser facility at Livermore.

E\&TR Celebrates 20 Years

Energy and Technology Review celebrates its 20th Anniversary in this April 1995 issue of the publication.

\section{Research Highlights}

Laser Fabrication of Beryllium Components

The Kinetic Energy Interceptor: Shooting a Bullet with a Bullet

Patents

Abstracts 


\section{Creating Microsphere Targets for Inertial Confinement Fusion Experiments}

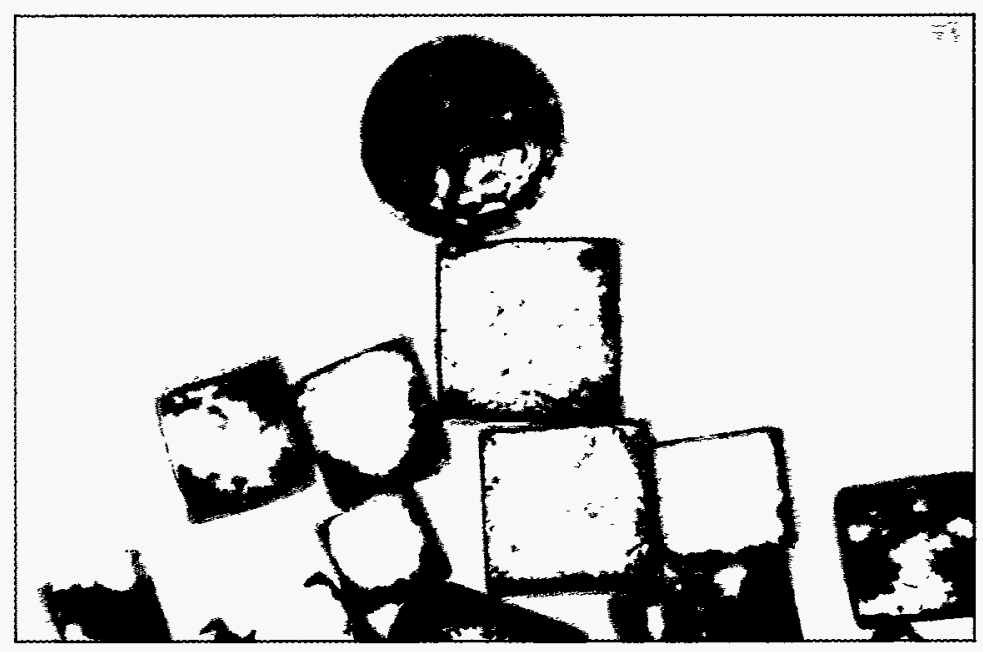

\section{At the heart of inertial confinement fusion (ICF) experiments are tiny, hollow microspheres used as targets. Their size, materials of construction, production methods, and structural characteristics have evolved to meet the demands of doing experiments on high-powered lasers such as Nova.}

$\mathbf{W}$ HEN heavy isotopes of hydrogen are fused to create energy, the nuclei of the isotopes must be confined as a plasma for a period of time, depending on the density and temperature of the plasma. In a star, this confinement is accomplished by the force of the star's gravity. In the laboratory, two approaches are being pursued currently. In magnetic fusion, strong magnetic fields are used to contain relatively low-density plasmas for a few seconds. In inertial confinement fusion (ICF), the confinement times are no longer than 100 picoseconds ( $1 \mathrm{ps}=1$ trillionth of a second), but the plasma densities achieved can be greater than the density of lead.

At Lawrence Livermore National Laboratory, these high-plasma densities are achieved by symmetrically depositing several kilojoules of energy from the powerful Nova laser system on a small plastic capsule containing the gaseous isotopes of hydrogendeuterium $\left(\mathrm{D}_{2}\right)$ or deuterium-tritium (DT)-over a period of a nanosecond ( $1 \mathrm{~ns}=1$ billionth of a second). The deposited energy ablates the capsule wall, and the rocketlike blowoff of the hot surface material compresses the interior fuel. Although the laser system that provides the energy is as large as a football field, the target containing the fuel is only about a half millimeter in diameter. The success of each ICF experiment using this large, complex machine depends greatly on the structure and our characterization of these tiny targets. Their size, structure, and materials of construction must be perfectly suited to the particular ICF experiment for which they are used so that the resulting data can be appropriately interpreted. For more than 20 years, therefore, research concerning the design, structure, production, and performance of these capsules has been an integral part of the Laboratory's Laser Program. 


\section{ICF Target History}

Targets for the first ICF experiments at LLNL were glass shells produced from an aqueous glass solution. Small droplets of this solution were dried in a heated drop tower to form hollow shells. These

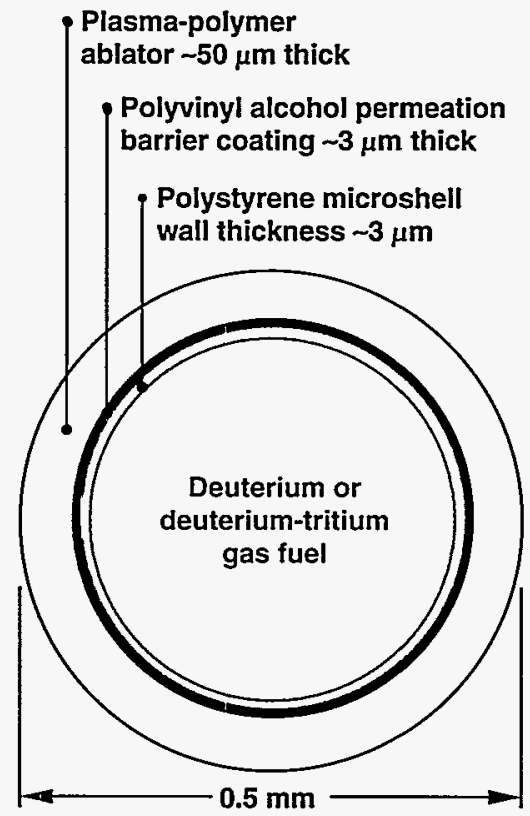

Figure 1. A typical ICF capsule, which is built around a thin polystyrene microshell. This microshell is first coated with a thin polyvinyl alcohol (PVA) layer, which serves as a permeation barrier to the gaseous fuel fill. A relatively thick ablator layer is applied using plasma polymerization techniques. These composite capsules are then filled with a precise amount of deuterium or deuterium-tritium by placing the capsule in contact with the fill gas at high pressure and elevated temperature. glass targets, 70 micrometers $(\mu \mathrm{m})$ in diameter, offered the advantages of high strength, low gas permeability, easy doping with diagnostic atoms, and excellent symmetry and surface finish. As the laser drivers improved, larger and higher quality glass shells were fabricated. However, the high

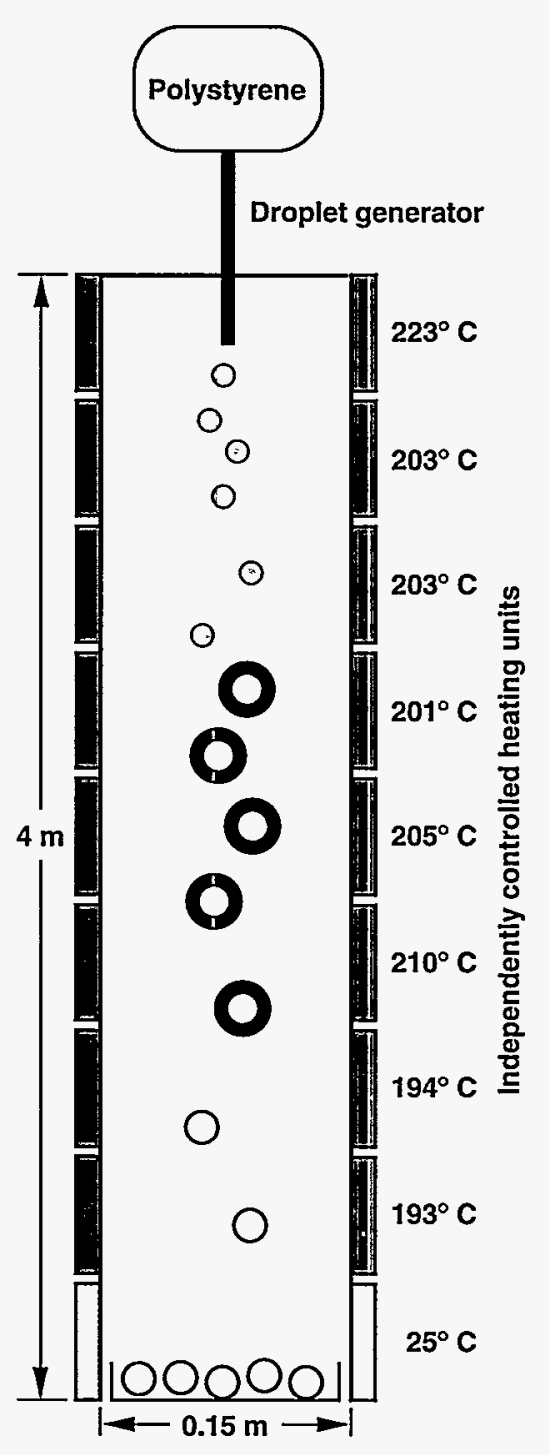

Figure 2. Diagram of the heated drop tower (not to scale) used to produce the microshells. Droplets of polystyrene (PS) solution $400 \mu \mathrm{m}$ in diameter fall down a 4-m-high column whose temperature profile is controlled by nine independent heating units. Several thousand shells 400 to $500 \mu \mathrm{m}$ in diameter can be produced in just a few minutes. density and atomic mass of glass limited the variety of possible experiments, and so an alternative material with a lower atomic mass was sought.

Polyvinyl alcohol (PVA) shells appeared to be an excellent alternative to glass. These shells were also prepared using heated drop-tower technology. Droplets of PVA solution about $200 \mu \mathrm{m}$ in diameter with internal argon bubbles $100 \mu \mathrm{m}$ in diameter were generated using a dualorifice system. In the heated droptower column, these hollow droplets dry to form high-quality shells with diameters up to about $250 \mu \mathrm{m}$. PVA, unlike most other polymers, is particularly well suited as a capsule material because it is an outstanding diffusion barrier to the hydrogen isotopes that fill the targets to fuel ICF experiments. However, attempts to extend the size range of PVA shells to meet the needs of Nova experiments were unsuccessful, and so yet another material was sought.

\section{Current Target Capsules}

The current ICF target capsule is built around a roughly one-halfmillimeter-diameter polystyrene (PS) microshell and is composed of three layers (Figure 1). The innermost PS microshell is produced by the solution drop-tower technique illustrated in Figure 2. The process begins with a $4.5 \mathrm{wt} \%$ solution of monodisperse PS (molecular weight $=98,500$ ) in dichloromethane that contains $3.0 \mathrm{wt} \%$ 2-propanol. The droplet generator provides uniform drops with diameters of about $400 \mu \mathrm{m}$. The drops fall through a 4-m-high tower composed of nine individually heated subunits. The first eight are heated to about $200^{\circ} \mathrm{C}$; the bottom unit is kept at room temperature to cool the shells. Several thousand 400 - to $500-\mu \mathrm{m}$ diameter shells are typically made in a run lasting a few minutes. 
The shell formation process is shown in Figure 3. Initially, as the PS solution droplets fall down the tower, they shrink due to evaporation of the volatile dichloromethane solvent. As the solvent evaporates, the concentration of polymer grows near the drop surface. During this period, the drop is being heated by the surrounding gas but is cooled by evaporation. As a polymer membrane forms at the surface (accelerated somewhat by the less volatile 2-propanol, which does not dissolve PS), evaporation of the solvent (and thus cooling) is inhibited and the droplet begins to heat. When the droplet temperature exceeds its boiling point, an internal vapor bubble forms, and the shell inflates quickly. During shell expansion, evaporation is enhanced because the polymer-rich layer is thinned, allowing for better solvent transport to the surface, while the surface area is increased. The final size and quality will depend on the cooling rate and symmetry of the hot PS shell.

It is also possible to use these techniques to prepare microshells doped with small concentrations of atoms with high atomic numbers that are used as diagnostics in various ICF implosion experiments. These doped microshells are prepared from polystyrene or polystyrenelike copolymers in which the desired diagnostic atom has been bound to the polymer chain. Typical dopants are chlorine, bromine, iodine, iron, chromium, and, most recently, titanium.

The PS microshell is then coated with 2 to $3 \mu \mathrm{m}$ of PVA, the second layer of the target capsule. This layer is necessary because PS is a poor barrier to hydrogen diffusion, and the hydrogen-isotope fuel that is eventually put in the target would leak out before it could be used. The PVA layer is applied by collecting several hundred PS microshells in a capillary tube, drawing a $10 \%$ aqueous PVA solution up around them, and then expelling them into a second heated drop tower. The solution around the individual shells dries as they fall down the tower. The efficiency of this step is low: typically the number of "target-quality" shells recovered is less than $5 \%$ of the total run. Shell loss is due largely to uneven coatings and particulate adhering to the PVA coatings.

The third and outermost capsule layer, called the ablator, is typically 30 to $60 \mu \mathrm{m}$ thick and is deposited using plasma polymerization coating techniques. A mixture of hydrogen and $t$-2-butene at a combined pressure of about 70 mTorr is fed through a glass tube wound with wire connected to a $40-\mathrm{MHz}$ radio-frequency (rf) power source. This rf power creates a plasma in the tube that breaks up the organic feed gas into molecular fragments that rain down onto the PVA-coated microshells that are agitated in a bounce pan below. The coatings produced are heavily crosslinked polymeric material and are applied at rates from 0.3 to $1.0 \mu \mathrm{m} / \mathrm{h}$, depending upon the feed gas pressure and power. For some target designs, we dope the ablator with 1 to $2 \%$ germanium atoms to modify the energy absorbing properties of the coating during the implosion. This doping is done by adding a small amount of tetramethyl germane to the feed gas flow. The plasma-polymerization coating process produces a very smooth coating with a peak-to-valley variation of $100 \AA$ ( 1 angstrom = 1 ten-billionth of a meter, or $10^{-10}$ meter) or less.

\section{Capsule Performance}

In an ideal implosion experiment, a perfectly uniform, intense energy flux would bathe a perfectly smooth and spherical capsule, ablating the outer plastic coating and compressing the fuel inside. In this situation, the performance of the capsule, generally measured as neutron yield, would depend only upon the power delivered to the capsule surface. However, in real experiments, capsule performance is degraded due to both spatial nonuniformities in the energy flux and

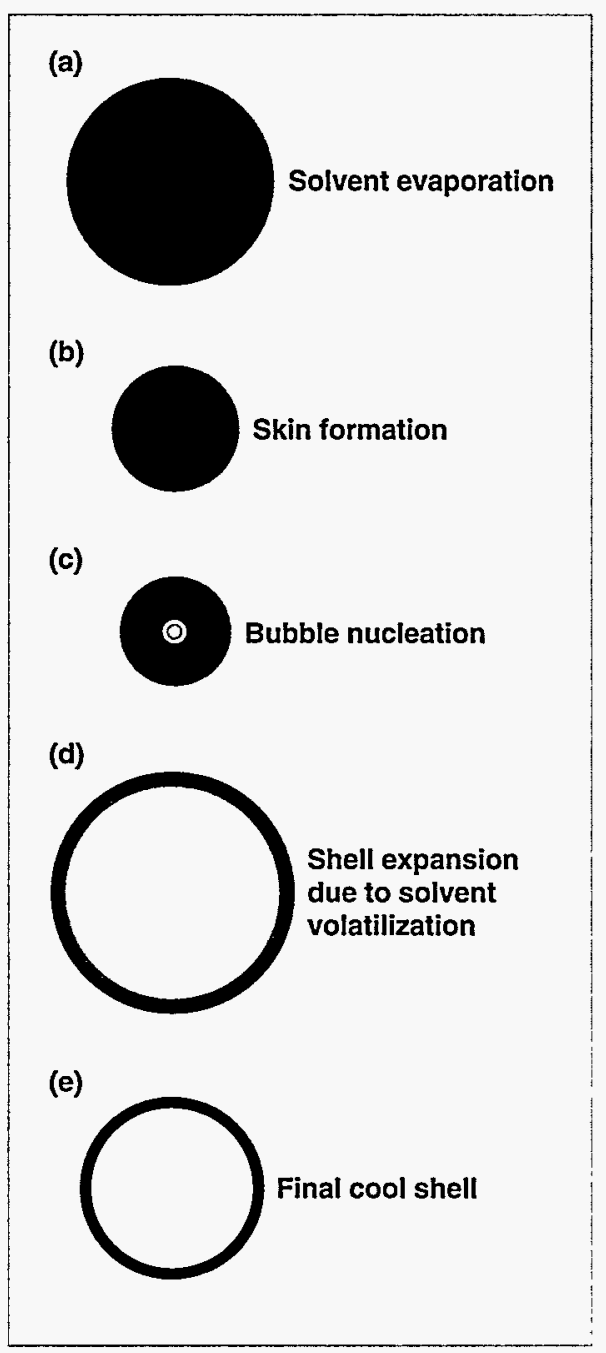

Figure 3 . The shell formation process begins when the solvent rapidly evaporates from the polymer solution droplet (a) and a skin forms at the droplet surface (b). The skin retards evaporation, and the droplet begins to heat. When the droplet temperature exceeds its boiling point, a vapor bubble forms inside the shell (c) and inflates rapidly (d). The final size and quality of the shell (e) depend on the cooling rate and the symmetry of the hot PS shell. 
capsule imperfections. In very simple terms, the basic principle is that the smoother and more symmetric the energy flux or capsule, the more even and efficient the implosion. Conversely, the more uneven the energy flux or rougher the capsule surface, the greater the target performance degradation, because hydrodynamic instabilities in the capsule during the ablation phase of the implosion lead to nonuniform and inefficient compression.

Because it is impossible to produce a capsule that is perfectly smooth and perfectly spherical, we are working to verify our understanding of the effects of capsule imperfections on ICF implosions through current Nova experiments. This verification is important to strengthen our case that we can produce a capsule that will ignite under the conditions planned for the National Ignition Facility (NIF). From the capsule point of view, these experiments have required us to develop the capability of making very precise measurements of what the capsule surface irregularities actually are. These measurements, which we call surface maps, provide the input data for the theories that predict capsule performance and allow us to compare experimental results with theoretical understanding.

Before we discuss how we measure capsule surface roughness and use this information to predict capsule performance, we need to understand the nature of the hydrodynamic instability mentioned above. Technically it is called RayleighTaylor instability, after Lord Rayleigh, who investigated it more than 100 years ago, and Taylor, who investigated it experimentally in the 1950s. The basic phenomenon is simple (Figure 4). Imagine a situation in which we very carefully create a layer of dense fluid on top of a lighter, less dense fluid. For the purposes of this example, think of the light fluid uniformly pushing against the dense fluid and holding it up. As long as the interface between the fluids is perfectly flat and horizontal, the fluids can remain in place. However, if a small perturbation is created at the interface, the system becomes unstable and the amplitude of the perturbation will grow, allowing the more dense fluid to flow down as the lighter fluid pushes up through it.

An analogous situation exists during the ablation phase of an ICF implosion. In this case, the less dense plasma created during ablation is pushing against the dense capsule surface. Perturbations on the surface grow during this process (Figure 5). That growth can lead to a degradation of the capsule performance because compression efficiency is lost and the growing perturbations cause the inner capsule surface to mix with the fuel and cool it.

The degree of growth of perturbations on a capsule surface depends upon their "mode number." To understand this concept, suppose we trace Earth's surface, starting at the north pole, passing through the south pole, and returning to the north pole. This trace looks like a circle. A more careful measurement, however, shows that the diameter of this circle is a little less if measured between the poles than if measured at the equator. This type of asymmetry is called a "mode 2" feature, because it has two cycles per circumference.

ICF capsules also generally have a mode 2 asymmetry that can have an amplitude of a few micrometers, or about $1 \%$ of the capsule radius. Although this is by far the largest amplitude asymmetry in a capsule, it is relatively stable during the (a)

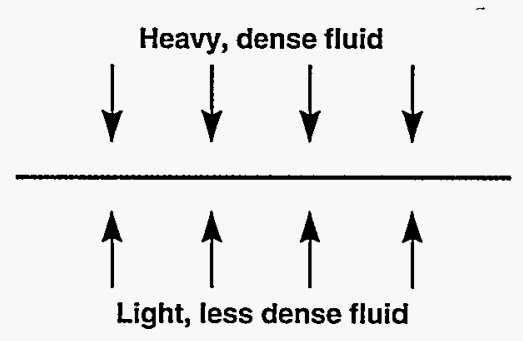

(b)

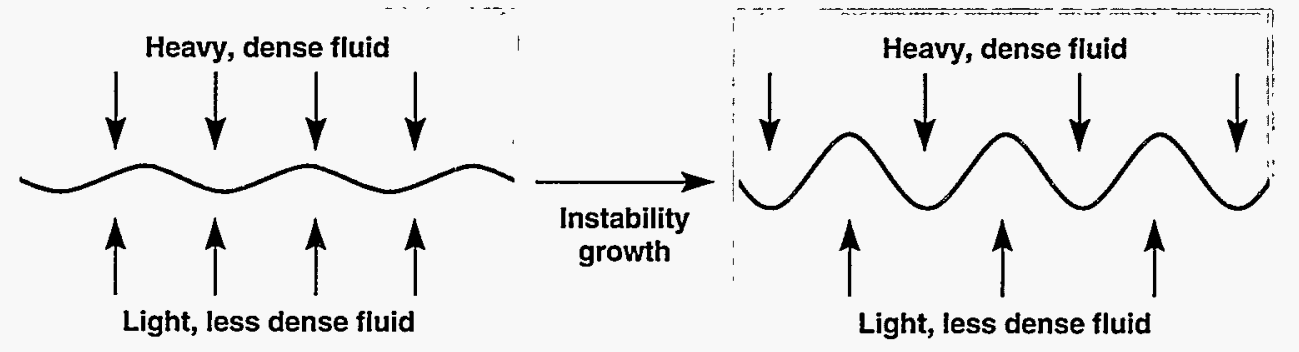

Figure 4. Illustration of the concept of the Rayleigh-Taylor instability that degrades ICF capsule performance. (a) As long as the interface between a heavy, dense fluid and a light, less dense fluid is perfectly flat and horizontal, the fluids can remain in place. (b) However, if a small perturbation is created at the interface, the system becomes unstable and the amplitude of the perturbation will grow, allowing the more dense fluid to flow down as the lighter fluid pushes up through it. In an ICF implosion, low-density ablated plasma is pushing against the dense capsule surface; thus surface perturbations at the capsule surface are Rayleigh-Taylor unstable and grow as illustrated in Figure 5. 
implosion and does not grow appreciably.

Consider again our trace of Earth. If we look very carefully over very short distances along the trace, we see small bumps with amplitudes up to a few hundred feet due to trees and houses, and over even shorter distances, smaller bumps due to people, stones, and blades of grass. This manifestation of surface roughness in the Earth trace represents extremely high mode numbers but relatively low amplitudes. High mode defects of this kind are also present on ICF capsules, but they also do not grow appreciably during the compression. Intermediate between the very low mode features and the high mode features are modal features between, say, mode 10 and 100 (at length scales between one-tenth and one-hundredth of the trace circumference). In our example of the Earth trace, these are features like continents or mountain ranges on continents. The amplitudes of these features would be from one to several miles (approximately $0.025 \%$ to $0.1 \%$ of Earth's radius), much less than the amplitude of Earth's mode 2 asymmetry and much greater than he amplitudes of the higher mode features.

ICF capsules also have surface roughness in this modal range, at lateral length scales between a few tens to a few hundreds of micrometers and amplitudes up to approximately $0.025 \%$ of the capsule radius. It turns out that the amplitudes of these modes grow the most during the implosion, and thus control of surface roughness over these modes is extremely important.

\section{Mapping the Capsule Surface}

To understand, and thus predict, the effects of capsule surface roughness on performance, we have had to develop ways of mapping capsule surface roughness, particularly in those modal regions that lead to the maximum growth during the implosion.

Because of the sensitivity of the Rayleigh-Taylor instability to mode number, it is important to be able to characterize the capsule surface asymmetries over lateral length scales

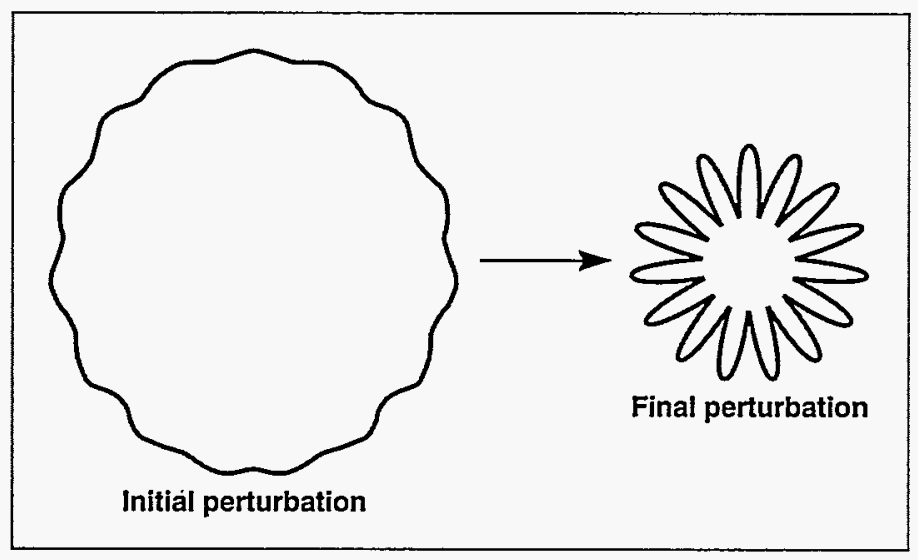

Figure 5. During an implosion, small amplitude perturbations on the capsule surface can grow by factors of 100 or more, depending upon the specific details of the perturbation and the implosion. This can lead to a degradation of capsule performance.

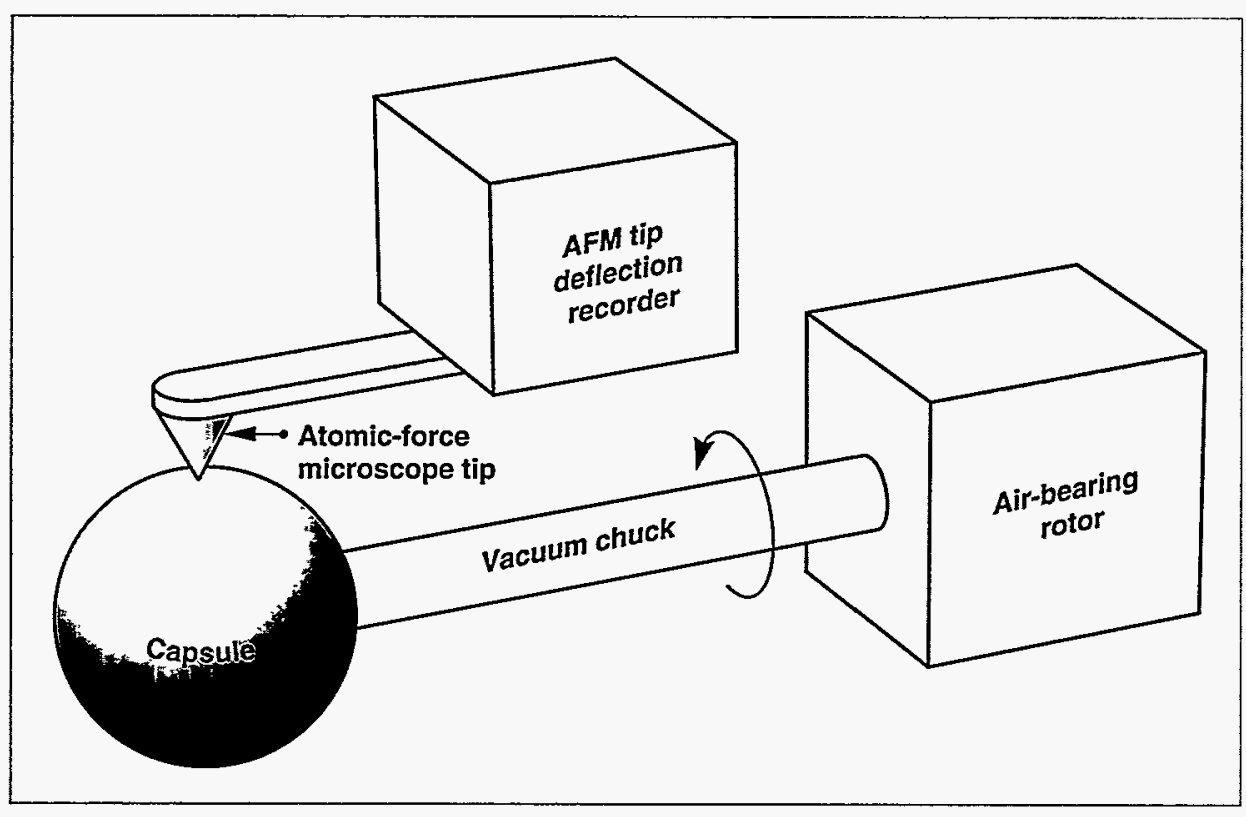

Figure 6. Schematic diagram (not to scale) of the Sphere Mapper, which is used to characterize the capsule surface finish. As the capsule is rotated, an atomic force microscope (AFM) records variations in the capsule radius to a precision of about $10 \AA$. Typically, three orthogonal sets of three traces are taken, as shown in Figure 7. 
capsule is rotated while the AFM records height measurements at 3600 evenly spaced points. Generally three sets of equatorial traces are taken: the Sphere Mapper takes traces at the equator and at $20 \mu \mathrm{m}$ above and below it; then the capsule is rotated 90 degrees and the process repeated; one additional 90-degree rotation gives us three orthogonal sets of three traces, as shown in Figure 7.

For comparison, typical trace data for a $1000-\mu \mathrm{m}$-diameter precision ball bearing made of silicon nitride

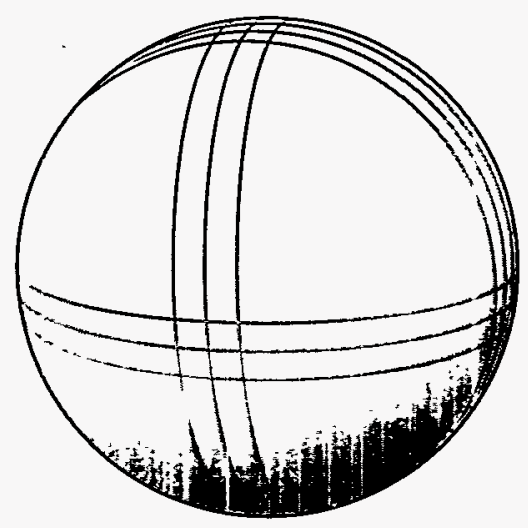

Figure 7. The Sphere Mapper takes three orthogonal sets of three traces to characterize the surface finish of ICF capsules. Example trace data are shown in Figure 8.

Figure 8. Typical trace data from (a) a silicon nitride ball bearing and (b) a titaniumdoped microshell. Note that the horizontal axis is in degrees of rotation. The translational distance along the capsule surface associated with 1 degree of rotation is given on each plot and is much greater than the displayed vertical scale. The relatively shallow, intermediate-length-scale perturbations of the microshell surface are associated with the largest Rayleigh-Taylor growth during an ICF implosion. and for a $435-\mu \mathrm{m}$-diameter titanium-doped microshell are shown in Figure 8. Note that the vertical scale is in tenths of micrometers while the horizontal scale is in degrees of rotation. The translational distance per degree is shown as an inset in each plot. Thus, the apparently sharp spikes in Figure 8a are in reality several micrometers wide. In the data in Figure $8 \mathrm{~b}$, the small bump at about 160 degrees is about $0.025 \mu \mathrm{m}$ high and $60 \mu \mathrm{m}$ wide.
Note that the ball bearing is extremely spherical but relatively rough on a short-length scale. In contrast, the capsule shows a significant (by comparison) mode 2 asymmetry but is locally extremely smooth. Also notable on this capsule are some intermediate-length scale perturbations, $20 \mu \mathrm{m}$ to approximately $100 \mu \mathrm{m}$ in breadth, with amplitudes of 0.01 to $0.1 \mu \mathrm{m}$. These are the kind of surface perturbations associated with large Rayleigh-Taylor instability growth, i.e., degradation of implosion performance,

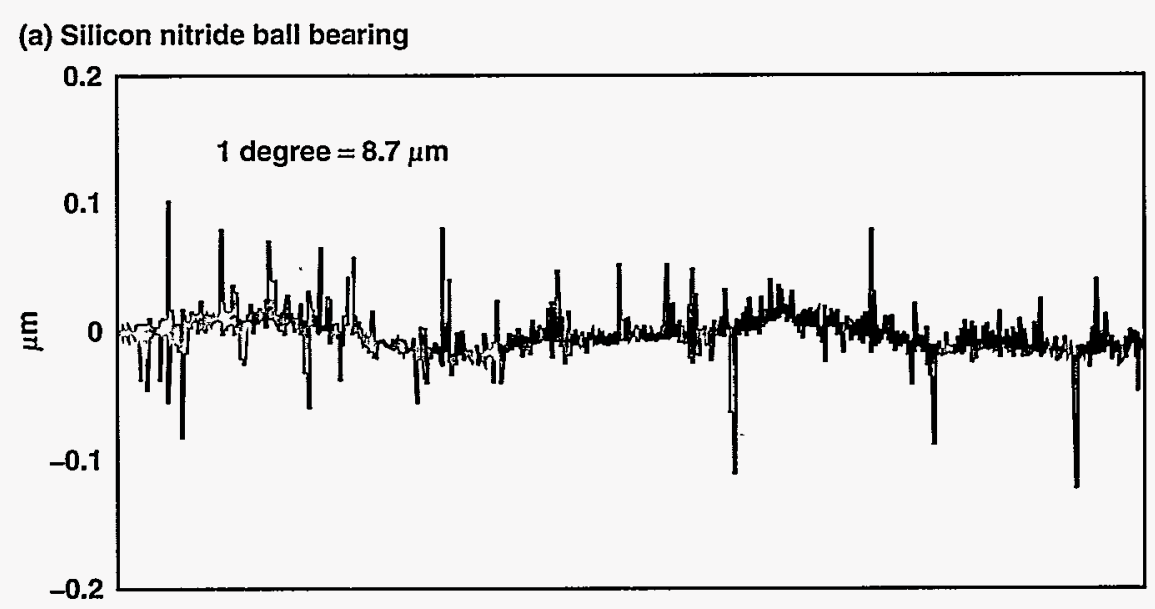

(b) Titanium-doped microshell

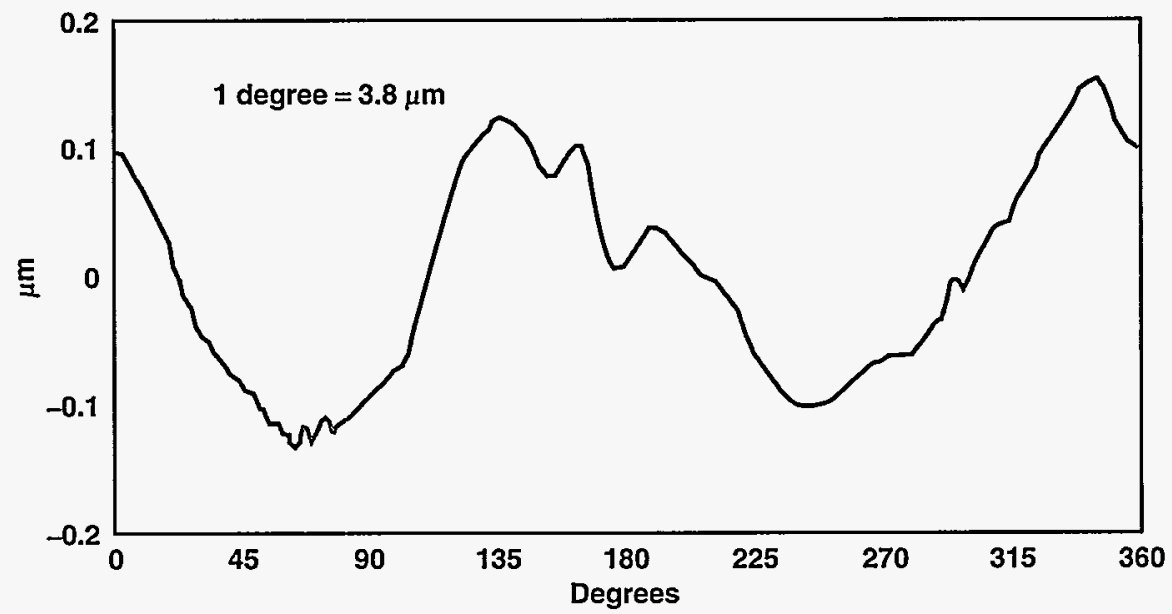


while the mode 2 asymmetry with an amplitude of about $0.3-\mu \mathrm{m}$ has little effect on an ICF implosion.

\section{Surface Modification}

To determine the effects of capsule surface finish on capsule performance, we developed controlled ways of varying the outer capsule topography. Initially we made use of the fact that the plasma-polymer coating is conformal, and that deliberate perturbations on the surface of the
PVA layer would manifest themselves in perturbations on the outside of the finished capsule. Our approach to roughening the PVA layer prior to plasma polymer coating was to include 2- to 4- $\mu \mathrm{m}$-diameter solid polystyrene microspheres in the PVA coating solution. These microspheres were thus incorporated into the PVA coating, producing a bumpy surface on the completed capsule as shown in the sketch at the left in Figure 9b.

In these experiments, incorporation of dopants in the polystyrene
Figure 9. On the left are sketches of (a) a smooth and (b) a bumpy capsule. On the right are the emission spectra obtained during the implosion of these capsules. The bumpy capsule (b) leads to more mix and thus a more intense chlorine signal than does the smooth surface (a). Data from experiments with modified targets such as this enable us to validate theoretical models of target performance. (a) Smooth surface

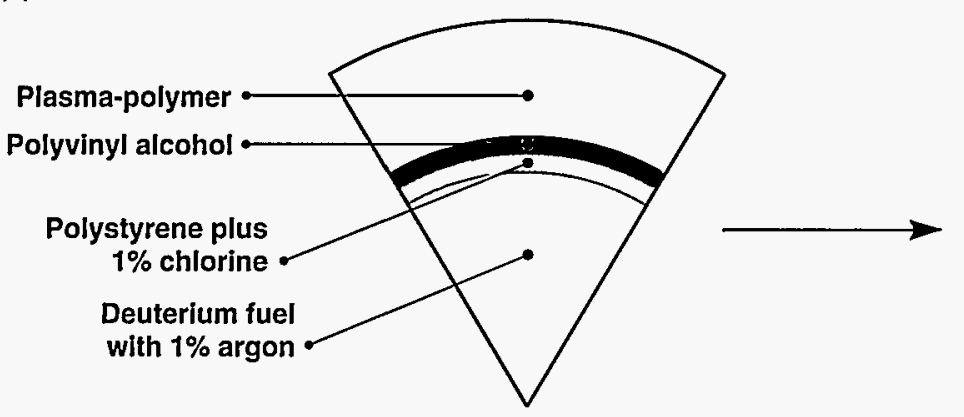

(b) Bumpy surface

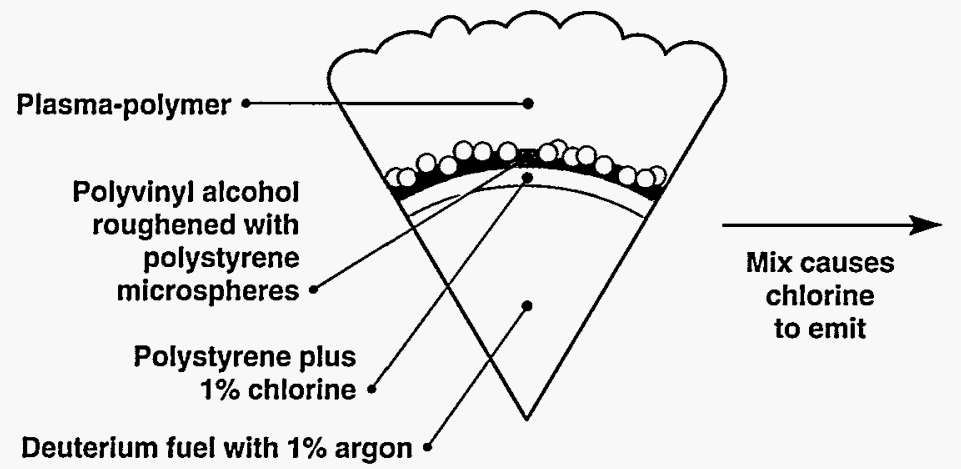

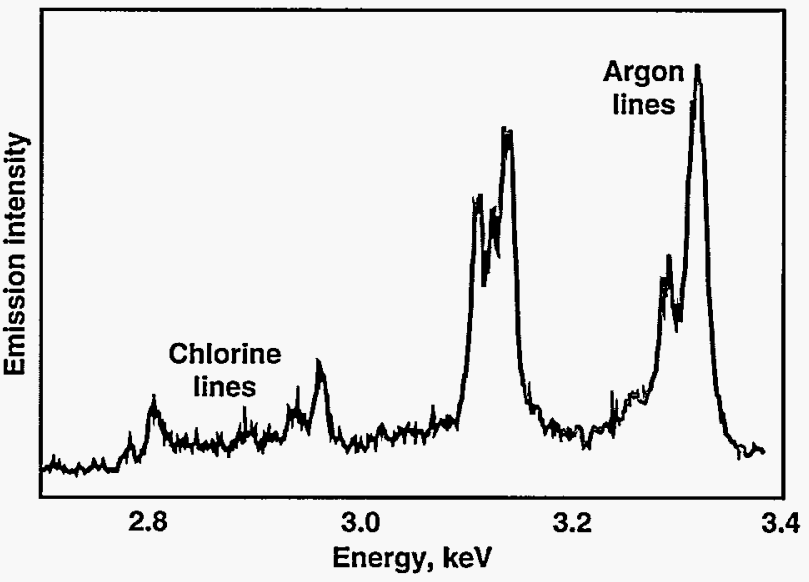

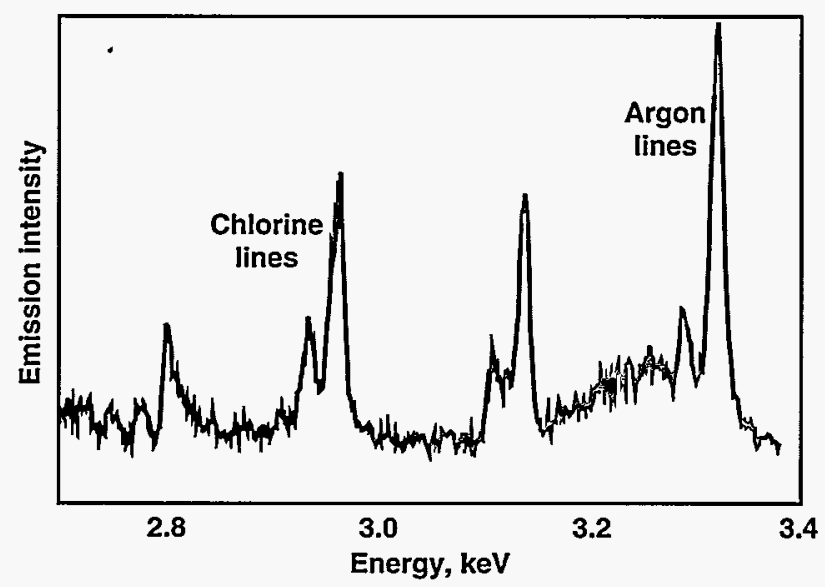


microshell and the gaseous fuel allowed spectroscopic diagnosis of the degree of "mix" of the inner capsule wall with the fuel due to the growth of surface perturbations. (Compare Figure $9 \mathrm{a}$ and $9 \mathrm{~b}$.) For a smooth capsule (Figure 9a), there was little mix, and the inner wall was kept well outside of the hot central fuel region, resulting in only a small chlorine emission in comparison to the emission from the argon dopant in the fuel. For the rough capsule (Figure 9b), however, the growth of surface perturbations resulted in a

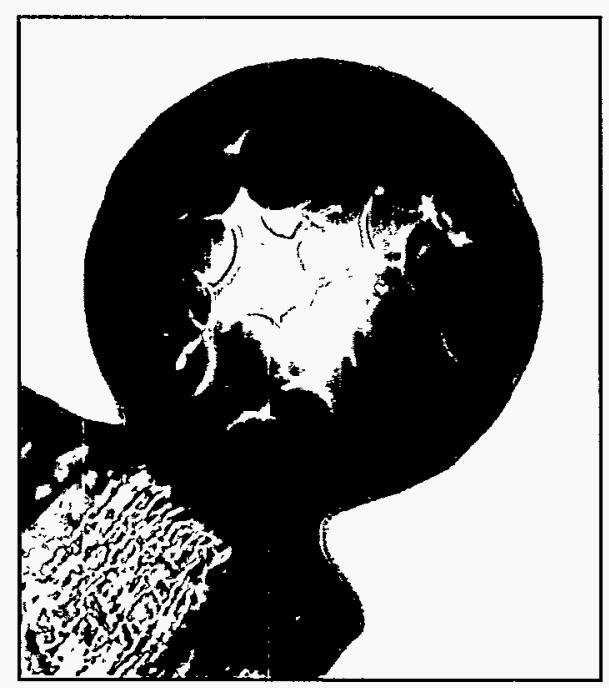

Figure 10. A 0.5-mm-diameter plasma-polymer-coated capsule with 200 randomly placed ablated pits, each about $75 \mu \mathrm{m}$ in diameter and $1 \mu \mathrm{m}$ deep. This capsule was intentionally roughened to a predetermined extent to study how surface perturbations affect capsule performance during an implosion. much greater chlorine emission signal when compared with the signal from the fuel argon dopant, indicating a significant mixing of the inner capsule wall with the hot fuel.

The use of polystyrene seeds in the PVA layer as a mechanism to produce roughened capsule surfaces offered only modest control over the degree of roughness. Recently we have developed the capability of using a laser to precisely carve pits with depths from 0.1 to $3 \mu \mathrm{m}$ and widths up to $100 \mu \mathrm{m}$ on capsule surfaces. In Figure 10, the photo shows a 0.5-mm-diameter plasma-polymercoated capsule with 200 randomly placed pits, each roughly $75 \mu \mathrm{m}$ in diameter and $1 \mu \mathrm{m}$ deep. The cover photo shows a capsule with symmetrically placed pits. The success of this technique for roughening capsules to a predetermined extent is proving extremely valuable in developing our understanding of Rayleigh-Taylor hydrodynamic instabilities during an implosion due to capsule surface perturbations.

\section{Future ICF Needs}

As the ICF community develops more powerful laser drivers, the capsules used in these experiments will need to be larger. The Omega Upgrade ICF facility at the University of Rochester's Laboratory for Laser Energetics will come on-line in the spring of 1995 and will require capsules that are roughly $1 \mathrm{~mm}$ in diameter. The National Ignition Facility (NIF), with a planned completion date shortly after the year 2000 , will require 2 -mm-diameter capsules. The production of these capsules will depend on the development of new technology, because our solution drop-tower methods are limited to approximately $0.5-\mathrm{mm}$ capsules, due largely to the large heat and mass transfers necessary.

A number of alternative technologies, however, hold promise for delivering larger capsules. The most widely developed is microencapsulation. In this method, a water droplet is encapsulated by a polymer solution and then suspended in an aqueous phase. The organic solvent containing the polymer slowly dissipates into the aqueous phase, leaving behind a polymer shell. This approach to shell manufacture has been used for a number of years at the Institute for Laser Engineering at Osaka University and also at the University of Rochester. In both cases, the typical polystyrene shells produced for ICF targets have been significantly less than $1 \mathrm{~mm}$ in diameter. Work is in progress to extend this technology to 1 - to 2-mm capsules suitable for Omega and NIF ICF experiments.

The target fabrication group at the Lebedev Institute in Moscow has historically made plastic shells for Russian ICF experiments by heated drop-tower techniques using particles of solid polymer infused with small amounts of volatile organic solvent that inflate the particles when they are melted in the drop tower. This approach is useful for larger shells because much less mass and heat transfer is necessary compared to solution drop-tower techniques. Using this technique, the Lebedev group has been able to routinely prepare $1-\mathrm{mm}$ capsules with good symmetry and surface finish. For larger shells, there is concern that the hydrodynamic interaction of the falling molten 
capsule with the surrounding atmosphere will lead to distortions. To remedy this problem, as well as to maximize heat transfer in the minimum drop-tower height, they have developed the concept of a "Ballistic Furnace." The polymer particles are injected up into the column so that they inflate to become hollow shells at the trajectory apex, when the hydrodynamic interactions with the surrounding media are at a minimum.

A route to larger shells as well as unique capsules for current ICF experiments is being developed at LLNL based on the use of decomposable solid or hollow mandrels. Briefly, the method makes use of the fact that poly ( $\alpha$-methylstyrene) thermally decomposes to a gas at a relatively low temperature. It is possible to prepare very symmetric and smooth solid beads or hollow shells of this polymer at sizes up to several millimeters, overcoat them with a layer of plasma polymer, and then heat them to decompose the poly $(\alpha$-methylstyrene) mandrel, leaving a symmetric shell of the desired size. The method may also be useful for preparing capsules with prescribed inner surface roughness by using the laser ablation technology discussed earlier to roughen the poly $(\alpha$-methylstyrene) mandrel before overcoating. In this way, the rough contours of the mandrel will be reproduced on the inside surface of the shell remaining after thermal treatment.

Future ICF target designs for both the Omega and NIF facilities call for cryogenic targets in which a $100-\mu \mathrm{m}$ thick, symmetric, solid or liquid $\mathrm{D}_{2}$ or DT fuel layer is present on the inside of the capsule wall. One route to accomplishing this is to prepare capsules with a low-density organic foam liner to hold the fuel inside the full-density plastic shell. Capsules of this type have been developed at Osaka University and at LLNL using microencapsulation techniques. The method involves microencapsulating a droplet of water or oil by a $100-\mu \mathrm{m}$-thick layer of an oil or water phase, respectively, which contains about $5 \%$ polymerizable components. This layered droplet is suspended in the same phase as the inner droplet. By initiating polymerization of the dilute monomer in the layer, a solid but low-density foam structure can form. This foam shell can then be overcoated with a full-density layer and finally dried to produce the desired foam-lined capsule.

\section{Summary}

The production of ICF capsules, with their very stringent symmetry and surface finish requirements, and the characterization of them represent major materials science challenges. The quality of the capsule is largely dependent upon the quality of the thin-walled plastic microshell around which it is built. The characterization requirements for the capsules have led to the development of new and unique capabilities for measuring their surface topology. The scientific interest in studying the effects of surface topology on the implosion dynamics has led to methods of precisely modifying the capsule surface finish. Future ICF targets will require larger capsules, and technologies designed to meet this need are now being developed.
Key Words: drop-tower technology; inertial confinement fusion (ICF) target capsules; microshell; microsphere; mode growth; National Ignition Facility (NIF); Nova laser; Rayleigh-Taylor hydrodynamic instability; Sphere Mapper.

Notes and References

This article is based on a paper delivered by invitation to the 1994 Symposium of the Materials Research Society in Boston, Massachusetts, November 28-December 2, 1994: Production of Microspheres for Inerial Confinement Fusion Experiments, Lawrence Livermore National Laboratory, Livermore, California, UCRL-JC-117389, 1994. The paper will also be reprinted in "Hollow and Solid Spheres and Microspheres-Science and Technology Associated with their Fabrication and Application," Materials Research Society Symposium Proceedings, Vol. 372, ISBN: 155899-274-X, 1995.

Robert Cook wishes to acknowledge the contributions of Russell Wallace, Randall McEachern, and other members of the ICF Program at LLNL who have contributed to the work described here.

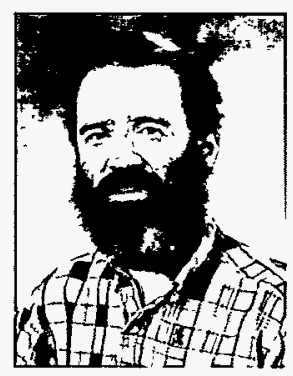

For further information contact Robert Cook (510) 422-3117, rcc@llnl.gov. 


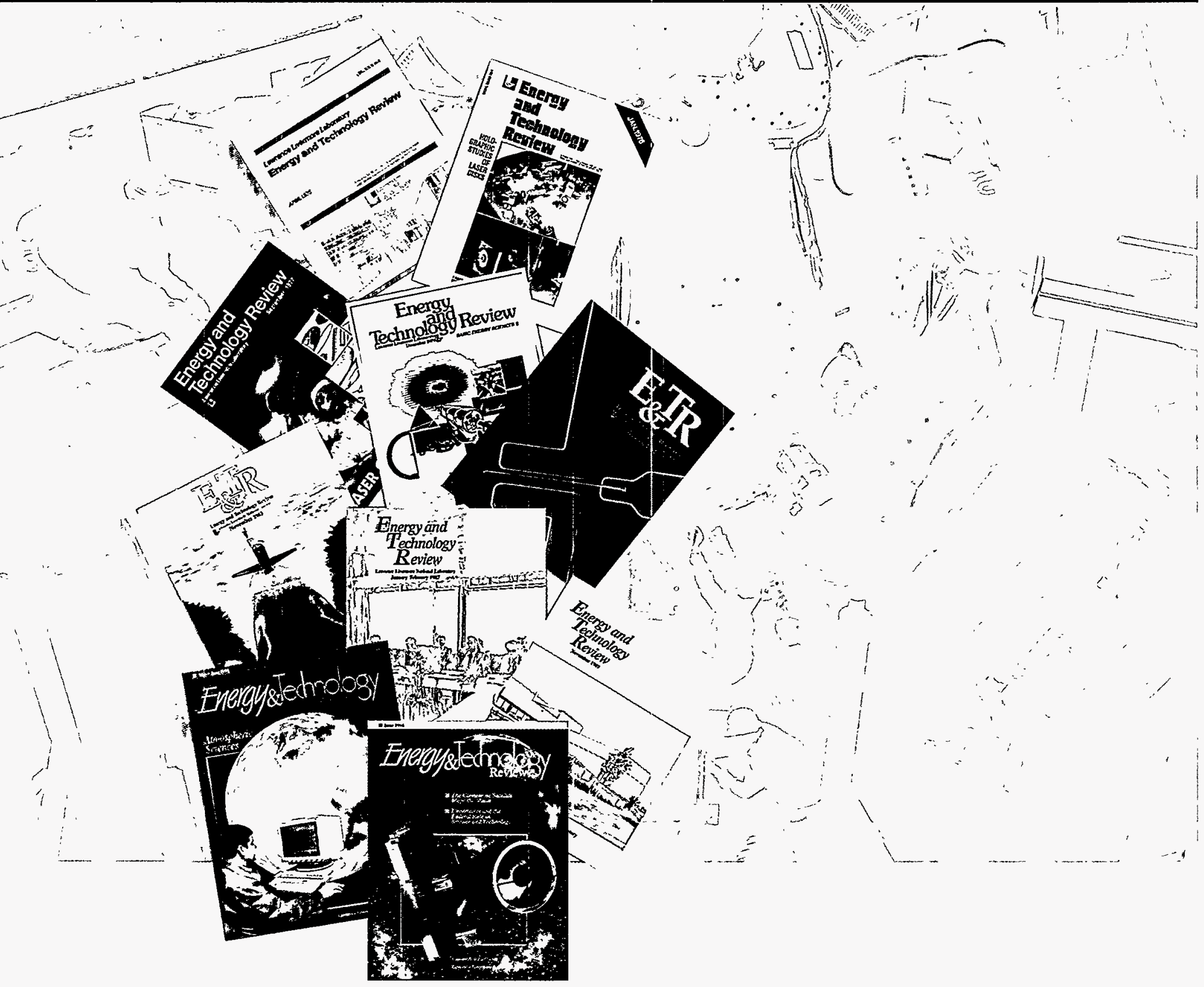

\section{E\&TR Celebrates 20 Years}

Reporting LLNL'S Scientific and Technical Accomplishments NERGY and Technology Review
celebrates its 20th anniversary this month as a public showcase for the quality and diversity of LLNL science and technology. LLNL's technical diversification in the late 1960 s and early 1970 s and the need to communicate with new programmatic sponsors were among the factors that led to $E \& T R$ 's creation.
"Today, a journal that brings the Laboratory's R\&D expertise into focus for the scientific community, funding sponsors, and the public is even more essential," says retired Associate Director Carl Haussmann, who helped nurture $E \& T R$ during its formative and pre-teen years.

"There is such a wealth of competing information and, in some sense, competing institutions that 

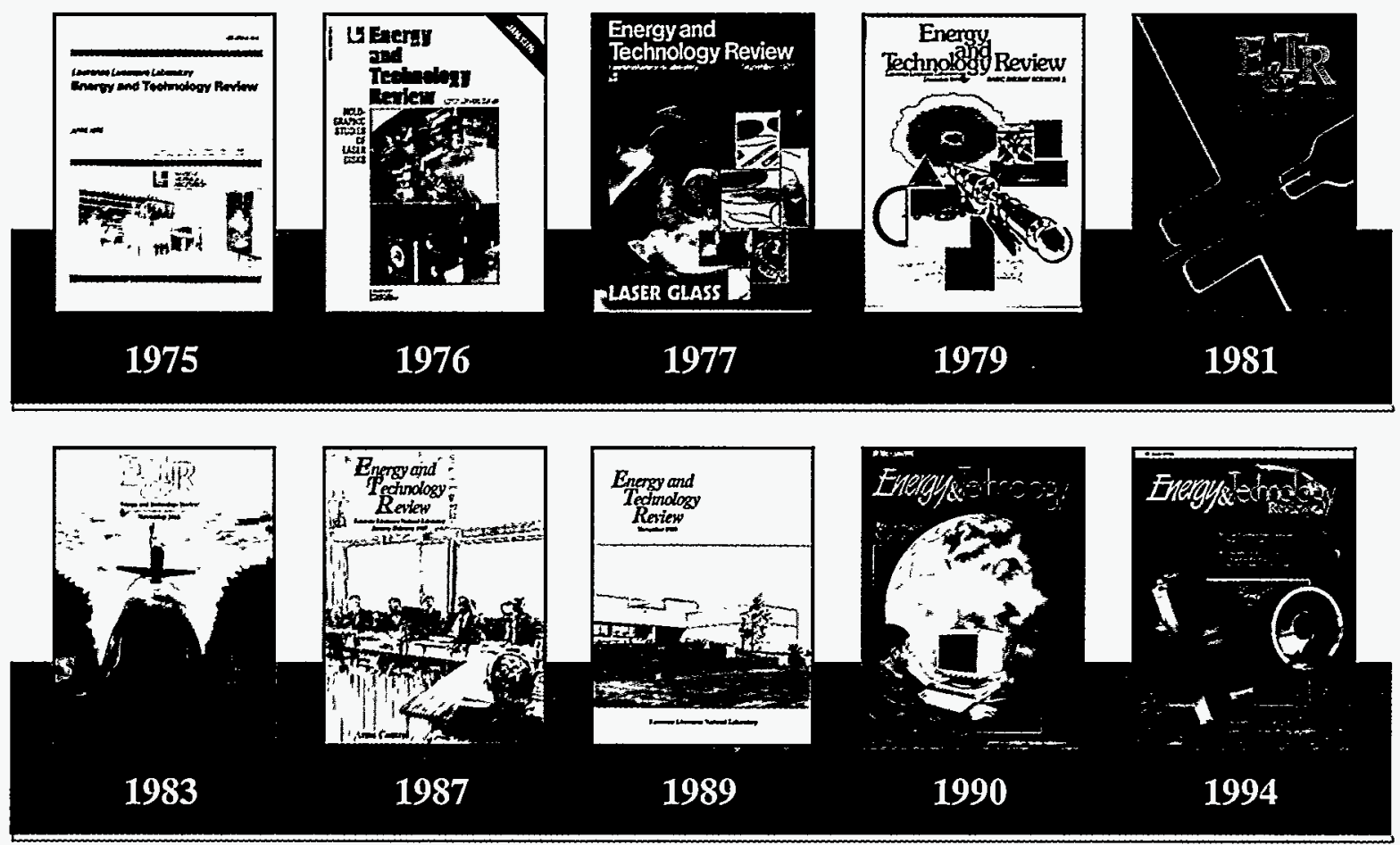

you want to project your work as much as possible," said Haussmann. "It also is important to get a reality check with the world; communicating your work to the public and private sectors is one way to do that."

Agreeing with Haussmann is Bob Barker, assistant to the director and program manager of the LLNL's Department of Defense activities. "As its customer base diversifies," said Barker, "LLNL finds itself dealing with more people who don't understand the breadth of the Laboratory's capabilities."

"E\&TR's broad coverage of the Lab's technical capabilities provides an ideal mechanism for making new potential customers aware of what we could do," said Barker, who has had the Director's Office oversight responsibility for $E \& T R$ since 1993.

$E \& T R$ debuted in April 1975 to report on the Laboratory's growing and relatively young programs-in energy, the environment, lasers, atmospheric sciences, and bioscience-that were added to the

\section{Design Changes Over the Years}

Make $E \& T R$ so visually appealing that a reader can't resist wanting to read the articles: That has long been one of the primary marching orders for the graphics staff of Energy \& Technology Review.

In response to that direction, $E \& T R$ has gone from a relatively staid black and white report to a journal that uses the most modern graphics tools to foster comprehension of LLNL's scientific and technological accomplishments.

Instead of simply using authorprovided photographs, graphs, and diagrams, the $E \& T R$ graphics staff often develop completely new illustrations or have photos taken that will help convey the author's message.

Issues have featured 3-D computer graphics, illustrations of complex experiments not yet built, and even renderings of phenomena that cannot be seen by the human eye, as was the case in a recent article about an astronomical experiment to detect massive compact halo objects, or MACHOS.

While use of color, cover design, and publication layout all evolved in response to each Scientific Editor's preferences or goals, now-retired Associate Director Carl Haussmann was a key figure during the graphics makeover in the early 1980 s.

"Carl was always interested in the appearance and quality of the report, and was always pushing for the use of color," said Lyle Cox, who was a member of Haussmann's staff at the time.

Haussmann said he wanted $E \& T R$ to successfully compete with other publications for a reader's attention. "If the content of your document is good-and I thought the content of $E \& T R$ was already pretty good-then the name of the game is to have your document picked up because of its mode of presentation." 


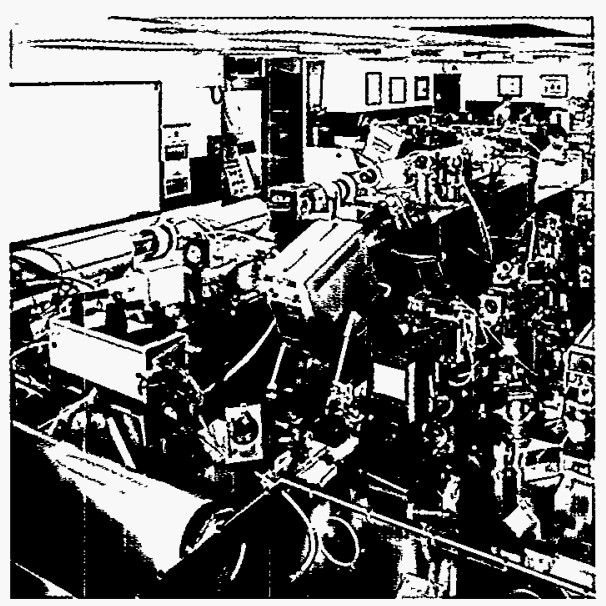

(E\&TR February 1976) Janus, LLNL's first two-arm laser system, consisted of a dyemode-locked oscillator, preamplifiers, beamshaping optics, and a series of neodymiumdoped, glass disk amplifiers with optical isolators. Most components were the same as in our single-arm Cyclops system. This laser drove our first successful inertial confinement fusion experiments in 1974. original missions of nuclear weapons $R \& D$ and magnetic fusion energy research.

The chief reporting vehicle prior to $E \& T R$ 's creation was a classified monthly report, Research Monthly (renamed National Security Science and Technology Review in 1993), that for nearly two decades had been prepared for the Atomic Energy Commission's (AEC's) Office of Military Application. Its focus was on the Lab's classified nuclear weapons research activities.

Research Monthly traces its roots to the LLNL monthly external progress report, first issued at the end of September 1952, the month the Laboratory opened. "That humble report consisted of nine typewritten pages, with nary a figure or table, and was stapled inside an ordinary file folder and handstamped with the appropriate classification markings," said Bob Berlo of the Technical Information Department (TID).

Berlo, who was a general editor on Research Monthly at the time $E \& T R$ was born, said copy for the classified report was written by Laboratory scientists and did not begin to receive extensive editing until 1964. By 1968, a team of two

(E\&TR November 1976) The lunar surface magnetometer deployed at the Apollo 16 landing site. The boot prints indicate scale. The golden ribbon is a power and signal cable. Together with an orbiting magnetometer aboard Explorer 35, this and other instruments provided a continuous iecord of changes in the magnetic field on the Moon over many months. (NASA Apollo photo.) to three TID editors was assigned to handle the growing publication. As the Lab's research mix changed in the 1970s, so did the classified monthly's content. On some occasions, half of Research Monthly contained unclassified articles.

Haussmann remembers a meeting in which Mort Mendelsohn, then head of Biomedical and Environmental Sciences, argued strongly for an unclassified companion to the classified journal. Said Haussmann: "It was clear that the director and the associate directors thought it was a good idea, so we proceeded."

The job of rounding up contributors for the first $E \& T R$ fell to Phil Coyle, then a young mechanical engineer who, in 1974, had been appointed to the term position of Scientific Editor for Research Monthly. Each Scientific Editor since Coyle has had responsibility for the scientific content of both the classified and unclassified journals.

Coyle was enthusiastic about the idea of an unclassified publication that publicly shared Laboratory science and technology, and "deserves a lot of the credit for E\&TR's creation," said Lyle Cox, who, along with Jim Frank, has been a central member of the Director's Office "monthlies" team. Coyle, as

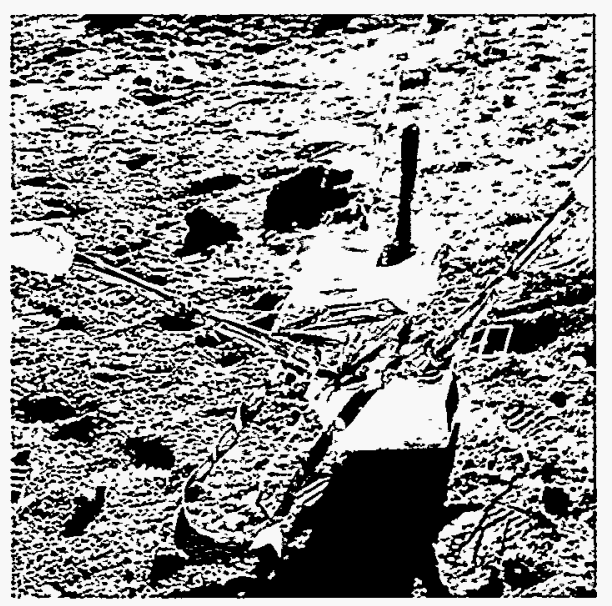


Principal Laboratory Associate Director, eventually inherited the E\&TR and Research Monthly oversight roles from Haussmann. Coyle retired in 1993 and is now Director of Operational Test and Evaluation in the Office of the Secretary of Defense.

$E \& T R$ was oriented initially toward two audiences - the Laboratory itself (primarily the scientific and technical staff), and its new sponsoring agency, the Energy Research and Development Administration (ERDA, which was created to replace the AEC; the Department of Energy succeeded ERDA in 1977). An additional audience-the nation's academic and industrial communities-was also expected to have a strong interest in the Laboratory's technical achievements. Frank undertook the job of creating $E \& T R$ 's external distribution list. By the end of the second year, the list had grown to 370 individual recipients.

Articles in the first $E \& T R$ addressed research in astrophysics, lasers, and fossil, solar, and magnetic fusion energy. Titles ranged from "Shallow Solar Ponds: An Economic Approach to Industrial Process Heat" to "An Overview of the LLL In Situ Coal Gasification Program."

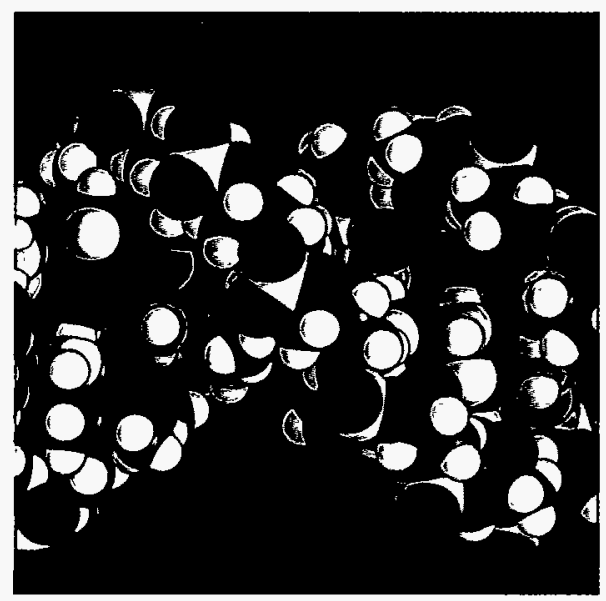

The Laboratory's "mirror reactor" approach to magnetic fusion energy discussed in the inaugural $E \& T R$ has since given way to an international effort focusing on tokamaks. "LLNL's solar pond and coal gasification research, both of which were continuing when $E \& T R$ celebrated its 10 th anniversary, have developed into semicommercial projects," said Bob Schock, acting Associate Director for Energy. "The Army installed solar ponds at one base, and several companies successfully implemented UCG (underground coal gasification). Both programs were very much ahead of their time and were victims of the falling price of oil as much as anything else."

A reading of the $E \& T R$ index for 20 years reveals the history of other LLNL programs that continue to register technical achievements. The Laser Program is a good example. From the July 1975 article on "Progress in the Calculation of Laser-Plasma Coupling," E\&TR has tracked the evolution of inertial confinement fusion research, from Shiva to the planned National Ignition Facility. And it has followed the development of atomic vapor laser isotope separation, from concept

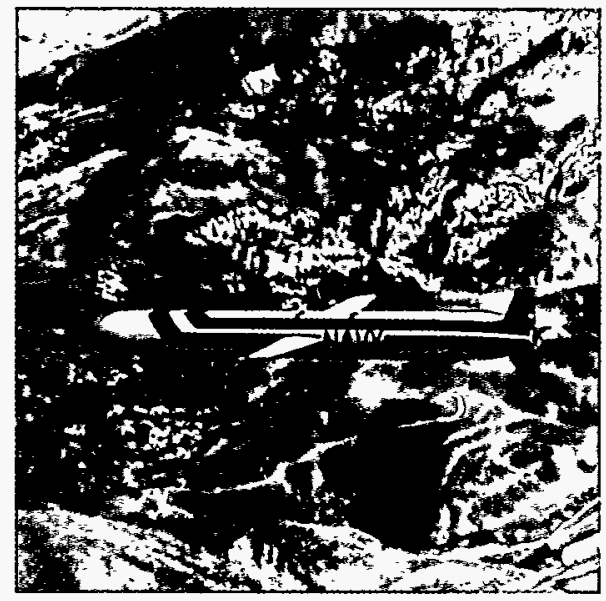

(E\&TR July 1981) The "State of the Laboratory" issue illustrated the status of weapon designs for the U.S. stockpile. Here is shown one LLNL warhead project then under development. The W84 groundlaunched cruise missile, authorized in October 1976, was in the production engineering phase.
(E\&TR November 1981) Computer-graphic modeling of a double helix of 20 base pairs of DNA. 


\section{$E \& T R$ 's Scientific Editors}

Since Research Monthly has had scientific editors, beginning in 1960 , the LLNL Director's Office has viewed appointment to the position as an opportunity to provide a "broadening experience" to a (usually) younger member of the Laboratory's technical staff-someone who displays potential for future leadership.

"If you look at the careers of the people who have held the job, you'll see they have benefited from the experience," said Carl Haussmann, Associate Director Emeritus. "It is one of the most notable opportunities at the Laboratory-being given the job of finding out what is going on, and making sure that it gets reported."

The list of scientific editors includes Director Bruce Tarter; Bob Barker, currently assistant to the Director; and retired Associate Director Phil Coyle, now Director of Operational Test and Evaluation in the Office of the Secretary of Defense.

The editorial tenures of Tarter and Barker came before the creation of Energy and Technology Review. Both filled the position during a period when the scientific editor focused his attention exclusively on the Laboratory's classified journal. Beginning with Coyle, the scientific editor was given responsibility for guiding the unclassified Energy and Technology Review and its classified companion.

For Ron Carr, E\&TR's second scientific editor, the greatest satisfaction during his tenure "was the opportunity to see many different parts of the Lab, and to learn a lot about the different programs and technologies."

Former scientific editors Stein Weissenberger (1980-81), Gordon Struble (1984-85) and Alan Burnham (1989-90) share Carr's views about the richness of the experience.

"The positive experience certainly, I think, outweighed the pain and heartache in pulling articles together," said Weissenberger, an electronics engineer who now is a program coleader in Transportation Technologies. "Clearly there could be no better way to get exposed to what was going on in the Lab. In that sense the job was extremely rewarding."

Said Struble, who at the time of his appointment was a Nuclear Chemistry group leader and is now deputy director of the Laboratory Directed Research and Development Program: "I came in with a very parochial view and learned a lot about the Laboratory."

Added Burnham, who was a member of Chemistry and Materials Science when he was tapped for the job: "I was struck by the vast diversity of high-quality work being done, and I'm convinced that no one even within the Lab truly understands all we are capable of doing." Burnham is currently a program leader in Energy Technology.

Although the Director customarily provides guidance to the scientific editor on the technical thrust of the journal, Tarter has displayed a much greater personal interest in $E \& T R$, said Lyle Cox. "I think it is because he had a good experience himself as a scientific editor," Cox observed.

Since the 1960s, Cox and his associate, Jim Frank, have handled a variety of Director's Office assignments for the Laboratory's external publications. In 1984, both filled in on an interim basis after scientific editor Frank Morrison died in a traffic accident. Cox also has served as a Director's Office "scout" for candidates for the position of scientific editor.

In the late 1960s, said Cox, he was asked by Haussmann to handle the background work on prospects for the position of scientific editor. "Since then I've been doing the annual beating of the bushes for a potential editor. It has been an enjoyable experience. Many of these people have gone on to become division leaders, which was the original checkpoint."
Appointed by the Director, a scientific editor serves for a year to 18 months. In addition to selecting topics and convincing scientists to break away from their day-to-day bench assignments to write articles about their work, a scientific editor works closely with the TID publications team to scope out each issue and shepherds article reviews. Sometimes the scientific editor must arbitrate differences between authors and general editors.

"Normally the TID editors deal directly with the author over the details of editing," remembers Weissenberger. "But in one case the author was so demanding and difficult that I was brought into the process. It was one of those interesting life experiences where you discover how personality, science, and politics can complicate your life."

Carr recalls how he used to get busy scientists to write articles. "They always had some excuse as to why they couldn't make the schedule. So I would get information on the topic they were trying to write and do the article myself. Since I did not have the background for the article, it would be technically and every other way wrong-and I knew it. I would give the article to the 'author' and say I was going to print it as shown. This got an immediate response-and a good article."

Weissenberger said one of his "fondest memories" relates to his experiences with Cox and Frank during the Director's Office review cycle.

"Lyle and Jim have two completely different personalities, but between the two you can cover the various parts of the publishing process," Weissenberger said. "Lyle is infinitely patient and sensitive to high-level issues, whereas $\mathrm{Jim}$ is certainly one of the most meticulous readers I have ever known. You can always count on him to go over a paper or draft with a microscope." 
to creation of an independent quasigovernment corporation that will industrialize the technology. Also unfolded through the pages of $E \& T R$ has been LLNL's development of laser applications to the manufacture of integrated circuits.

$E \& T R$ 's audiences have learned about Livermore bioscience developments in cell-sorting technology, the makeup of the human genome, and biotechnology. They have read about revolutions in microtechnology and microengineering, the significance of Livermore-developed materials such as aerogels and seagels, and the ways our R\&D is helping the nation regain its once-dominant economic position.

$E \& T R$ also has provided readers who don't have authorized access to National Security Science and Technology Review (formerly Research Monthly) with an unclassified look at the Laboratory's achievements in the national defense arena. Articles have ranged from nuclear weapons R\&D and techniques for verifying arms control treaties to emerging nuclear proliferation issues and post-Cold War nuclear weapons dismantlement activities.

$E \& T R$ introduced its first themed issue in August 1977 with an allLaser Program edition. Later

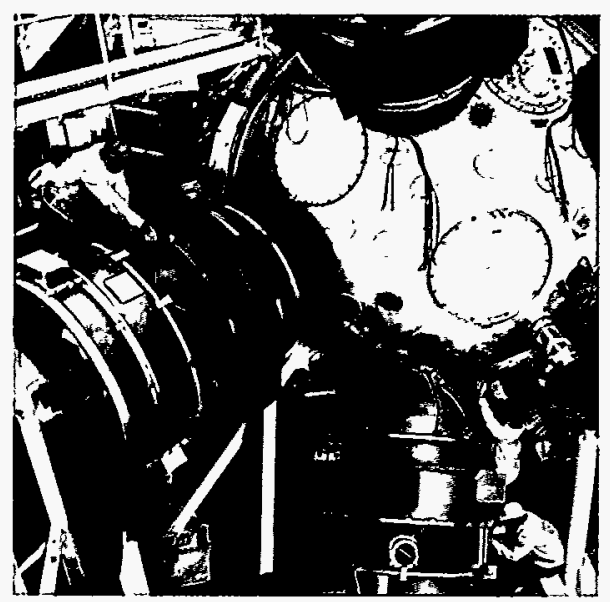

dedicated issues focused on areas such as computer graphics, astrophysics, high-pressure physics, accelerator mass spectrometry, and materials by computer design. One focused issue has recurred annually, the State of the Laboratory edition.

Kent Johnson, the scientific editor from September 1990 to September 1991, said he was surprised by the popularity of two $E \& T R$ issues under his tenure that "walked one step away from direct scientific results" and addressed topics "that had a little more flair." One was a dedicated issue on the Laboratory's educational outreach activities; the other contained several articles on cold fusion, which reported negative results.

Since $E \& T R$ 's beginning, the scientific editor and the Laboratory Director, or his representative, have decided what areas of Livermore research should be featured in the journal. The scientific editor then solicits articles from members of the scientific and technical staff and works closely with $E \& T R$ 's publication team-Technical Information Department (TID) editors, writers, graphic designers, photographers, and other production team members.

(E\&TR February 1985) The Nova target chamber, a massive aluminum sphere $4.6 \mathrm{~m}$ in diameter with walls almost $13 \mathrm{~cm}$ thick. The large flanges carry the frequencyconversion arrays and the final focusing lenses with their positioning mechanisms.

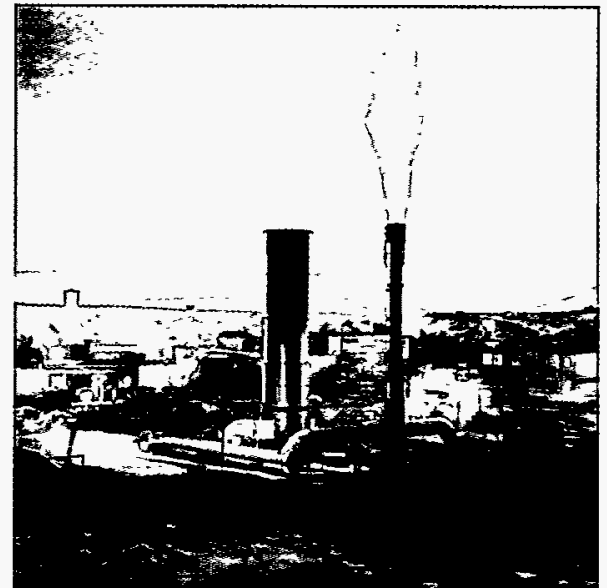

(E\&TR July-August 1989) The Rocky Mountain underground-coal-gasification test facility near Hanna, Wyoming. There we investigated ways to extract energy otherwise not exploitable. Coal was partially burned underground, and the gas produced could be upgraded to pipeline quality or used as a synthesis gas for liquid fuels. 


Ever ready with
advice and
enthusiasm
(from left to right)
Jim Frank,
Carl Haussmann,
and Lyls Cox
have played an
important role in
E\&TR since its
beginning in 1975.

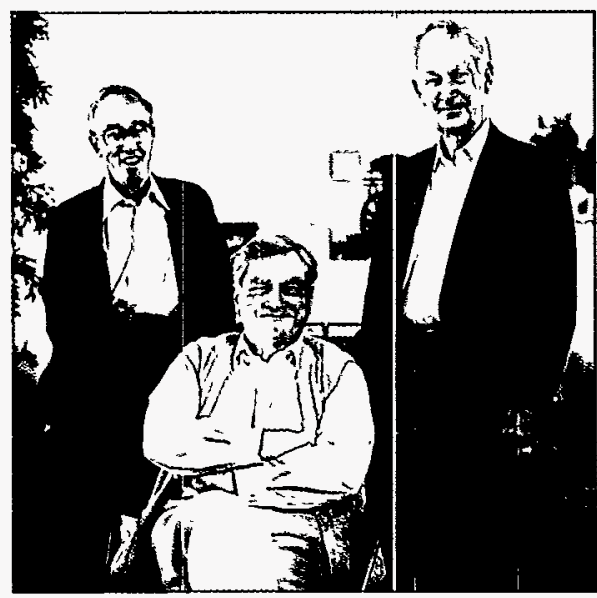

"It takes a considerable number of people to turn out these publications out," said Haussmann. "There are a lot of in-the-trench workers, people whose behind-the-scenes efforts make these things happen. The TID people-publication editors, writers, designers-have been major contributors over the years. The quality of their work has been impressive."

Helping an author shape an article into one that can be comprehended by people with dissimilar technical

\section{E\&TR's Scientific Editors: Where Are They Today?}

\begin{tabular}{|c|c|c|}
\hline Scientific editor & Editorial tenure & Current assignment \\
\hline William A. Bookless & 1994-present & Project Leader, Nuclear Weapons Information Project \\
\hline William J. Quirk & 1993-1994 & Primary Design and Intelligence Analyst \\
\hline Joseph A. Sefcik & 1991-1993 & Program Manager, A Division \\
\hline Kent C. Johnson & 1990-1991 & $\begin{array}{l}\text { Assistant Associate Director, Advanced Projects Office, Defense and Nuclear } \\
\text { Technologies }\end{array}$ \\
\hline Alan K. Burnham & 1989-1990 & Program Leader, Energy Technology Program \\
\hline Andrew J. Poggio & 1988-1989 & Deputy Division Leader, Engineering Research Division \\
\hline Richard D. Lear & $1987-1988$ & Associate Program Leader, B Division \\
\hline Hriar S. Cabayan & 1986-1987 & Manager, RF Weapons Effects Program \\
\hline Gordon L. Struble & 1984-1985 & Deputy Director, Laboratory Directed Research and Development Program \\
\hline Lyle A. Cox & 1984 & Staff to the Director \\
\hline James Frank & 1984 & Physicist \\
\hline Frank A. Morrison & 1983-1984 & Deceased 1984 \\
\hline Paul S. Brown & $1982-1983$ & $\begin{array}{l}\text { Assistant Associate Director for Arms Control, Defense, and Nuclear } \\
\text { Technologies }\end{array}$ \\
\hline Irving F. Stowers & 1981-1982 & $\begin{array}{l}\text { Science and Technology Advisor, Energy, Materials, Transportation } \\
\text { Technologies Program }\end{array}$ \\
\hline Stein Weissenberger & 1980-1981 & Program Co-Leader, Transportation Technologies Energy Directorate \\
\hline Erik Storm & 1979-1980 & Deputy Associate Director, Laser Programs \\
\hline Robert C. Haight & 1978-1979 & Technical Staff Member, Los Alamos National Laboratory \\
\hline Henry D. Shay & 1977-1978 & Senior Staff, Computation Organization \\
\hline Robert W. Selden & $1976-1977$ & Assoc. Director of Lab Development (ret.), Los Alamos National Laboratory \\
\hline Ronald B. Carr & $1975-1976$ & $\begin{array}{l}\text { ME Division Leader for Laser Program (ret.); now Lab Associate serving } \\
\text { DoD Office of the Secretary of Defense }\end{array}$ \\
\hline Philip E. Coyle & 1974-1975 & Director of Operational Test and Evaluation, Office of the Secretary of Defense \\
\hline
\end{tabular}

Editor's note: Scientific Editors also have responsibility for E\&TR's classified companion, National Security Science and Technology Review. Scientific Editors before the debut of E\&TR were: V. Alan Mode, 1973; C. Bruce Tarter, 1972; Robert B. Barker, 1971 ; George G. Staehle, 1970; Jim Kane, 1969; Richard Wagner, 1968; Van Hudson, 1967; George F. Bing, 1966; Bill Grayson, 1966; John W. Kury, 1965; Russ Duff, 1964; Harlan Zodtner, 1960-1963. 
backgrounds can turn into a demanding assignment, say scientific and general editors. Some authors, the editors say, are reluctant to have their writing red-penciled, feeling the editing process mightas Johnson puts it-"dumb down their work."

TID editor Lauren de Vore, an E\&TR editor from 1980 to 1994 , tells the story of one colleague who worked with a scientist who was "painstakingly helpful during the writing and editing process, but was

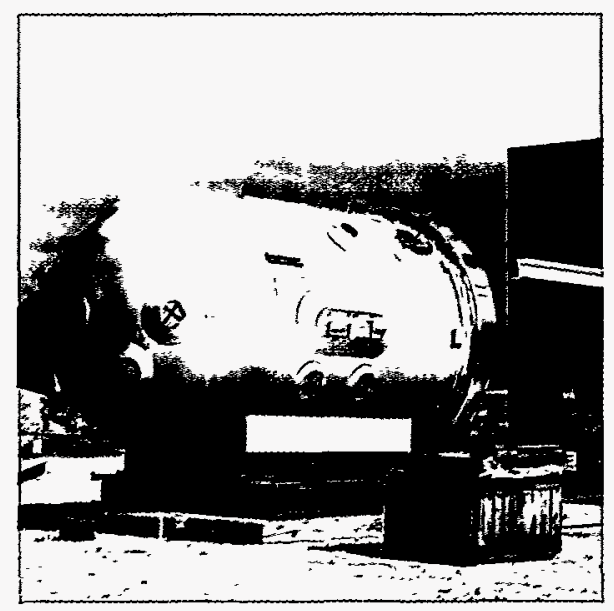

(E\&TR November 1989) The Laboratory's High Explosives Applications Facility's (HEAF's) cylindrical steel containment vessel, $3.6 \mathrm{~m}$ in diameter and $12 \mathrm{~m}$ long, shown prior to installation. It is used in experiments with a $100-\mathrm{mm}$-bore gun and for detonations of up to $5 \mathrm{~kg}$ of high explosives (TNT equivalent), but will be upgraded to withstand detonations of up to $10 \mathrm{~kg}$.

\section{Bruce Tarter on $E \& T R$ 's 20th Anniversary}

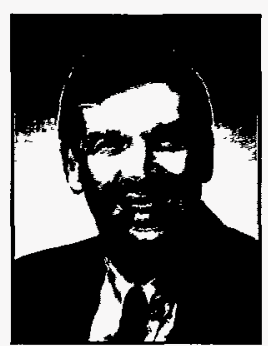

C. Bruce Tarter Director
For two decades, Energy and

Technology Review has played a vital communication role for the Laboratory. By reporting on the Laboratory's scientific and technological accomplishments, $E \& T R$ has helped its audience foster an understanding of the significance of our $R \& D$ contributions to the nation and the world.

Before $E \& T R$ 's creation, the Laboratory reported monthly to the Atomic Energy Commission through what evolved into the classified journal, Research Monthly (renamed National Security Science and Technology Review in 1993). The focus of Research Monthly, for which I had the pleasure to serve as Scientific Editor in 1972, was on the Laboratory's classified defense activities. In April 1975, E\&TR debuted as Research Monthly's unclassified companion, addressing growing programs in energy, biomedicine, and the environment, and the unclassified elements of the nuclear weapons program.

Significantly, the birth of $E \& T R$ came amidst a time of change, one similar to what we are experiencing today. New avenues of communication were required in the 1970s, necessitated in part by Congress' decision to abolish the AEC and create the Energy Research and Development Administration (itself replaced by the Department of Energy in 1977). For us at the Lab, that meant making our capabilities known to many people who were not intimately familiar with our record of technical success and R\&D contributions to the nation-program people who joined ERDA from other organizations and Congressional representatives on new oversight committees.

Today, $E \& T R$ provides a communication link with greater significance between the Laboratory and the outside world. We find ourselves interacting with an even wider spectrum of individuals and organizations who are not well acquainted with LLNL and the other DOE laboratories. Those in this category include the new Congressional leadership and their staffs; employees of federal, state, and local organizations with whom we have growing interactions; representatives of industry and consortia seeking to partner in areas of mutual benefit; and members of the general public who are curious about the role that national laboratories, particularly those with historically defense missions, can play in the post-Cold War world.

The Laboratory is committed to ensuring that we provide these new audiences with an understanding of what the Laboratory does and why. As part of this commitment, we have been looking at ways to position the publication for an even stronger communication role. We have taken two steps to further the commitment. First, we decided to rename the journal Science and Technology Review (S\&TR) to better reflect the Laboratory's current mission. Second, we are implementing improvements that range from new features and special sections on Lab science and technology to increase the journal's accessibility by making it available on the Internet. These changes will occur in the July issue, after a two-month publication hiatus. We are confident that $S \& T R$ will have a bright future: $E \& T R$ paved the way. 


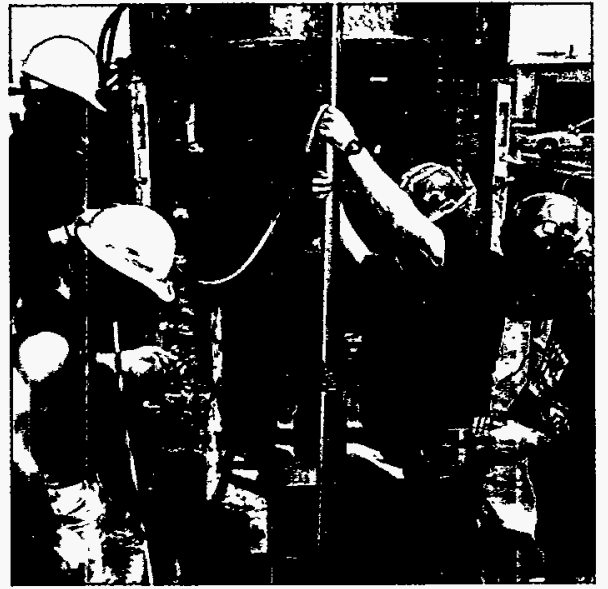

(E\&TR July 1992) Effective, rapid removal of underground hydrocarbon spills can be done with dynamic underground stripping. Workers are drilling a steam injection and electrical heating test well that will be used for controlled extraction of contaminants and associated groundwater from spills such as a leaking diesel fuel tank. never quite pleased. The author/ scientist indicated that because the article was so clear and readily understandable, he felt like we had trivialized his life's work," said de Vore.

"Most authors I have run across think they need no help whatsoever initially," said Haussmann, talking about reaction to the TID editing support and the pre-publication Director's Office review. “My suspicion is that when they (the authors) are done, they realize they benefited from the process."

As Haussmann sees it, the payoff to the author-and the Laboratory-is more than having a scientifically accurate, technically defensible article that can be understood by a wide spectrum of readers. The $E \& T R$ editing and review process also helps scientists develop into well-rounded communicators - a skill that has become increasingly valuable in an era when science is under close scrutiny from the public and Congress and explanation becomes a way of life.

During the 1970s and early to mid1980 s, articles tended to be fairly short (four to six pages). In the late 1980 s and early 1990 s, they typically

(E\&TR April-May 1992) A flow sorter designed and built at LLNL for high-speed sorting of human chromosomes in our Human Genome Center. This sorter features three lasers, state-of-the-art optics, and the latest computer technology, which together produce a versatile and powerful research tool for measuring the level of genetic injury in human cells. ran 10 to 12 pages, as more explanatory material and detailed illustrations were added so readers could understand more fully the significance of the accomplishment. Today, however, articles are shorter and more sharply focused to accommodate $E \& T R$ 's interested, educated, but non-expert readers who say they are too busy to spend time reading lengthy articles.

Electronic publishing is an additional feature for the technically rigorous reader who demands detail. As the Information Superhighway matures and extends its reach, $E \& T R$ will also be published electronically. Soon, in fact, $E \& T R$ readers will be able to click onto electronic links that will access an article's references to supporting documents, illustrations, and videos.

"When we do that, the whole world can tap into $E \& T R$ if they want. It will become available to everybody," explained Haussmann, who, although retired, maintains a fatherly interest in the publication he helped launch. Observed Haussmann: "In this era of greatly iilcreased information flow, $E \& T R$, both in paper and electronic form, has the potential of having more impact than ever."

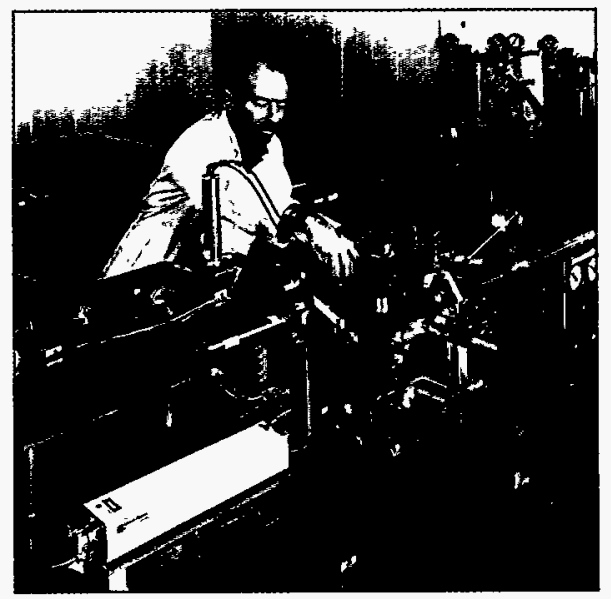




\section{Laser \\ Fabrication \\ of Beryllium Components}

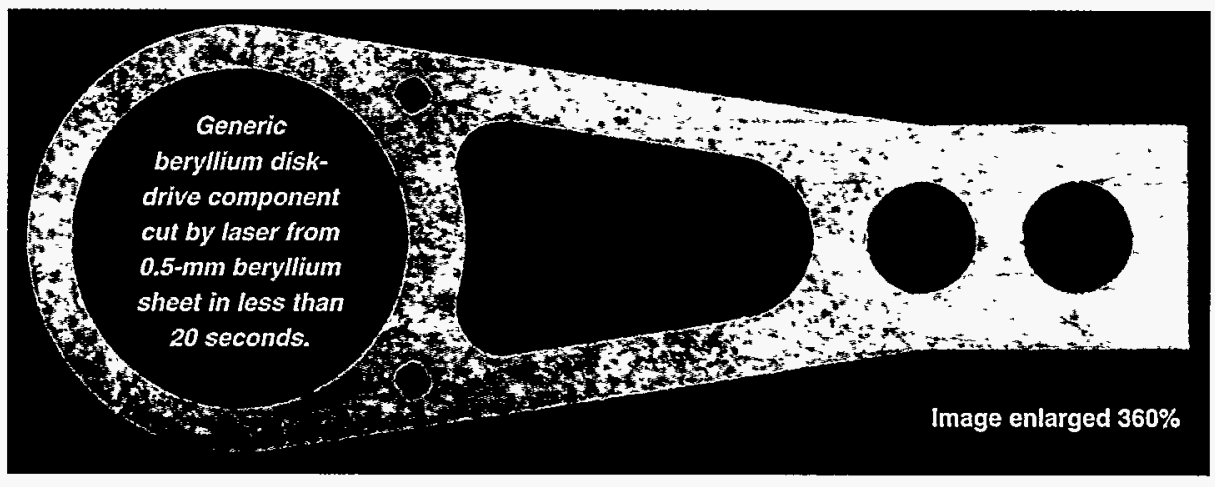

$\mathbf{H}$ ISTORICALLY, beryllium metal has been used chiefly for a relatively small number of parts in weapons and guidance systems and in a very few commercial applications. Beryllium's benefits more than offset the high cost and difficulty of fabricating parts; in fact, beryllium components often represent only a small portion of the total cost of the systems in which the components were used. Several new applications, involving small parts and high production rates, show that beryllium metal and alloys would clearly be the superior materials were it not for fabrication costs. Beryllium and beryllium alloys have several properties-low density, high modulus of elasticity, high mechanical damping capacity, and highfrequency resonance-that make them ideal for applications involving sheet product such as computer memory devices. Use of beryllium in drive arms and disk storage would allow more compact designs, leading to smaller, lighter disk drives and increased storage capacity.

\section{Problems and Solutions}

Even when great care is used, conventional machining can damage these hard, low-ductility materials, significantly impairing their mechanical performance. Moreover, there is no nondestructive method of detecting such machining damage. Competing materials can be stamped out of sheet product at a high rate, but to date beryllium cannot be stamped with any degree of commercial success.

Welding this low-ductility metal also presents problems. Conventional welding processes require use of a filler metal, that is, a different alloy from the metal being welded. Use of a filler is not desirable for some applications, but autogenous welding-welding without a filler-has been nearly impossible with beryllium.

Researchers at LLNL have found laser alternatives to the conventional methods of cutting and welding beryllium. We have been working with Brush Wellman Inc. (Elmore, Ohio), the only basic supplier of beryllium outside the former Soviet Union, on commercial applications and are using prototype parts. We demonstrated that lasers provide a high-speed, low-cost method of cutting beryllium metal, beryllium alloys, and beryllium/ beryllium oxide composites. In a separate project with Nuclear Metals Inc. (Concord, Massachusetts) and Space Power Inc. (San Jose, California), we developed laser welding processes for commercial structural grades of beryllium that require no filler.

\section{Laser Cutting}

For unique LLNL applications, we succeeded in cutting thin, high-purity beryllium foil long ago. Although laser cutting of structural sheet material containing significant amounts of beryllium oxide and impurities had never been tried, we proposed that lasers be used to cut commercial structural grades of beryllium sheet and, further, lasers might do so faster than conventional methods. Of several lasers at LLNL approved for use with beryllium, we chose two for our initial study: a 400-W pulsed YAG (yttriumaluminum-garnet) laser and a $1000-W$ continuous-wave carbon dioxide $\left(\mathrm{CO}_{2}\right)$ laser. In fact, our attempts were highly successful.

Both lasers easily produced acceptable surface finishes of the cut edges of beryllium parts. The alloy AlBeMet (from Brush Wellman Inc.) and beryllium/beryllium oxide composite sheet material were cut at thicknesses from $0.5 \mathrm{~mm}(0.020 \mathrm{in}$.) up to approximately $2.0 \mathrm{~mm}$. The $0.5-\mathrm{mm}$ sheet was cut at speeds up to $2.54 \mathrm{~m} / \mathrm{min}$., and thicknesses of 1.8 to $2.0 \mathrm{~mm}$ were cut at speeds of 0.5 to $0.8 \mathrm{~m} / \mathrm{min}$. The photo above shows a typical generic prototype part cut from a large, 0.5 -mm-thick beryllium 
sheet. The part's outline and six holes were cut in $18 \mathrm{~s}$. Most of this time was spent on relocating the part for cutting, rather than the cutting itself. On a microscopic scale, the cut edges were acceptable, and the part easily met tolerance requirements. In laser cutting, beam size determines the minimum radius possible, which is in the range of $25 \mu \mathrm{m}$ for our equipment. The smallest holes in the part shown have $1.0-\mathrm{mm}$ radii.

Laser cutting presents other benefits as well. First, the cut width created by material removal (the kerf) is narrow. Thus, the parts can be laid out very efficiently to yield more parts per sheet, and just as important, there is less beryllium waste for disposal. Second, there is no machining damage, as we determined by microscopic examination. We further confirmed this by cutting tensile specimens from the same structural beryllium sheet, and, with no further treatment after laser cutting, pulled them to failure. The mechanical properties (specifically, elongation to failure and ultimate strength) easily met and exceeded specifications. Third, for large-scale production, a more powerful laser could be used and the beam split to
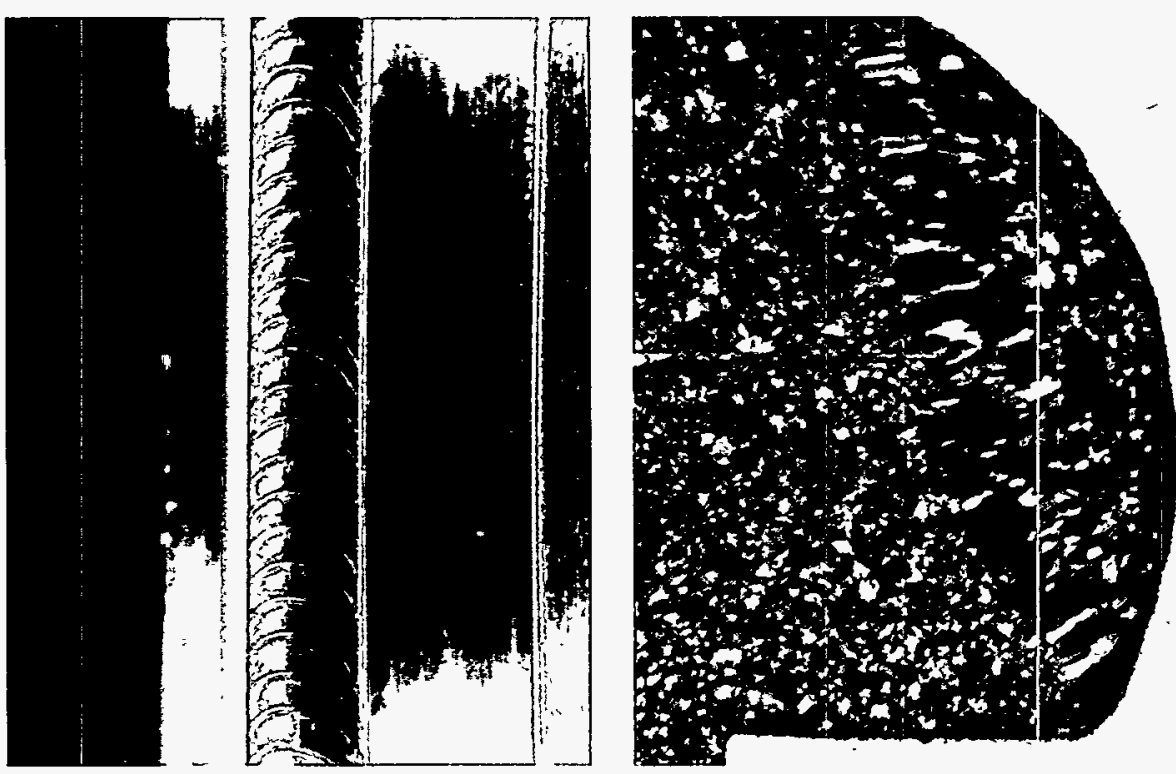

Autogenous laser weld in commercial structural beryllium. (Left) View of weld bead $25.4 \mu \mathrm{m}$ in diameter. (Right) Metallurgical cross section of a fusion zone (original magnification $100 \times$ ). cut several parts from a sheet at the same time. Fourth, a laser beam might be piped into a single designated room for beryllium cutting operations, reducing both the number of beryllium workers and the possible exposure of personnel to beryllium particulate.

\section{Autogenous Laser Welding}

Where possible, autogenous welding of metals is usually preferred to welding with fillers. Autogenous welding is a simpler process and results in a more homogenous junction of the two pieces being welded. In addition, operating temperatures may militate against the use of filler metal with a lower melting point. However, many metals and alloys do not lend themselves to autogenous welding, which is basically a complicated high-speed casting process.

Low-strength, ingot-grade beryllium has been welded autogenously for more than 30 years. For specialized applications that gave the welding metallurgist freedom in designing the weld, we have autogenously welded thin sheets of ingot beryllium with a laser. We also once autogenously welded structural beryllium using an electron beam. However, the more useful highstrength structural beryllium grades (powder-origin) have not been amenable to autogenous welding without severe cracking.

Several times over the past few years, we have been asked to make or design various specialized beryllium parts for satellites. Whether used for detecting signals from deep space or operating the satellite, these parts could have no foreign material-no filler material in the form of a weld or braze alloy. In the past, we successfully finessed the requirement by making very thin braze joints, usually with aluminum or an aluminum alloy. Recently, however, an application came to our attention in which even a thin braze line with a minimum of filler was not satisfactory. 
Through Nuclear Metals Inc., we learned that Space Power Inc. (SPI) needed beryllium caps joined to beryllium cylinders to encapsulate a nontoxic hydride. The cylinder would eventually be a component in a power source for a satellite, and the beryllium had to be the higher-strength structural grade. There were two reasons that the weld had to be autogenous. First, an element of higher atomic weight would harm the performance of the unit. Second, the cylinder operating temperature was more than $600^{\circ} \mathrm{C}$, which is above the melting temperature of virtually all welding filler alloys for beryllium. Any filler metal would violate one or both of these requirements.

Researchers at a commercial U.S. firm attempted to weld the cylinders using electron-beam-welding procedures but produced severe cracking. SPI obtained welded beryllium cylinders from Russia, but they leaked at temperatures above about $500^{\circ} \mathrm{C}$.

With our experience, albeit very limited, in autogenously welding beryllium, we offered to try laser welding the components. The cylinder was to contain an inert cover gas. Laser welding would serve well here, because the cylinder could be placed in a sealed chamber containing the gas and the cap welded to the cylinder by a laser beam passing through a glass port. For the development tests, the cover gas was not required, so we did not use the technique. We knew autogenous welding would be difficult because the required circumferential weld results in substantial residual stress, to which beryllium is not amenable. After considerable experimentation to determine the exact weld design and laser parameters, we succeeded in autogenously welding the cap on the 25.4-mm-diameter cylindrical component. Because of our experience in laser cutting, we preferred the pulsed YAG laser for our welding experiments, but the continuous wave $\mathrm{CO}_{2}$ laser has promise, as well. The left-hand photo on page 20 shows what a typical laser-weld fusion zone looks like; each individual ridge reflects the individual laser pulse. The right-hand photo shows some columnar epitaxial grain growth in the fusion zone. This growth is not desirable, but refining the welding parameters and slightly modifying the weld design should improve the microstructure.

The sealed cylinder containing the hydride was delivered to SPI, where it is providing excellent results with no leaking above $600^{\circ} \mathrm{C}$. This is the first successful application of autogenous laser welding of structural grades of beryllium.

\section{Summary}

Beryllium metal, beryllium alloy sheet, and beryllium/beryllium oxide composite sheets are all superior materials for use in various advanced technological applications, such as for improving computer speed and memory capacities. However, conventional machining techniques of these materials impose costs that make their use in commercial applications uneconomical. We have demonstrated that lasers can remove this economic barrier. Lasers can cut components to size at high speeds, with high tolerances and small radii without introducing machining damage, thus yielding high material efficiencies.

We have also shown that lasers allow beryllium to be used in applications requiring autogenous welding. We have autogenously welded commercial structural grades of beryllium.
For further information contact James $E$. Hanafee (510) 422-6928, jeh@llnl.gov or Terry J. Ramos (510) 422-9938, tjr@llnl.gov. 


\section{The Kinetic Energy} Interceptor: Shooting a Bullet with a Bullet

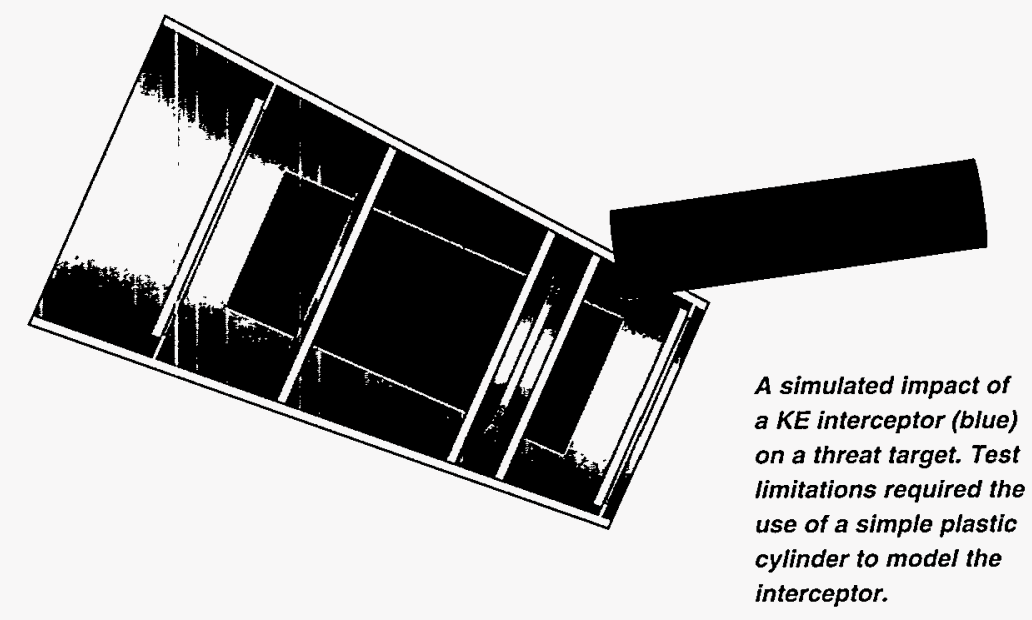

ATHOUGH the Cold War has ended, the threat of $A 1$ proliferation with chemical, biological, and nuclear warheads continues. Two factors further increase the threat from these weapons of mass destruction: knowledge of missile technology has spread extensively, and, in recent years, many countries-some of them unfriendly to the U.S. and its allies - have obtained short- and intermediate-range missiles. The threat posed by such missiles was amply demonstrated during the Gulf War. Thus, the need to protect U.S. and allied forces from these weapons has never been greater.

When nuclear-tipped defensive missiles, such as Sprint and Spartan, were phased out years ago, the U.S. turned for its defense to kinetic-energy "kill" interceptorsmissiles that destroy an enemy missile by striking it with lethal force and accuracy at some point in its trajectory. The Patriot missile is probably the best-known kineticenergy (KE) interceptor in the U.S. defensive arsenal. The Patriot. however, is a short-range interceptor. With continuing threats from various sources, the U.S. is also developing long-range $\mathrm{KE}$ interceptors.

To counter the spreading threat of proliferation, LLNL and other laboratories have been participating in a joint program funded by the Ballistic Missile Defense Organization (BMDO), within the Department of Defense, to develop defensive missile systems. Participants are designing, testing, and certifying $\mathrm{KE}$ interceptors to defend against current and future missile threats.

\section{The Joint Lethality Working Group}

The main criterion for a kinetic-energy interceptor is its lethality-its ability to destroy a threat missile without harm to the threat's target and with no collateral harm. (The destructive coupling of the defensive interceptor's kinetic energy into the incoming nuclear warhead has been likened to shooting a bullet with a bullet.) Within the BMDO program, the Joint Lethality Working Group focuses on the issues related to lethality. In addition to LLNL, the working group includes among its participants the U.S. Army, Air Force, Defense Nuclear Agency, Los Alamos National Laboratory, Sandia National Laboratories, and various government contractors.

The Joint Lethality Working Group is pursuing a program that combines experimentation with computer simulation and code development. Its goal is to design interceptors that are lethal to warheads that exist in present enemy or proliferant nations' stockpiles or are likely to be developed. Working group participants collaborate on the design of each experiment or series of experiments. They devise an interceptor design, a threat warhead design to test it against, and the particulars of the test-for example, relative velocities of the threat and interceptor at impact, location of impact on the threat, and angle of impact.

\section{The Interceptor Test Program}

While participants collaborate on test design, each separate participant assumes particular responsibilities. LLNL has several tasks within the group. Our chief tasks are to design, fabricate, test, and evaluate models of the nuclear warheads that intelligence reports indicate are within the technological capabilities of various foreign powers-those designs that U.S. interceptors might someday need to destroy in combat. In addition to designing targets, LLNL participates in establishing and defining the experiments in which interceptors are tested against targets. The challenge is to choose experimental parameters, such as projectile weight, closing speed, direction, and angle of incidence that will maximize the return of useful experimental data. To do that, we perform pretest code calculations to establish a test matrix to decide what we will do in a test and determine what results to expect. Then our post-test calculations give us the fidelity of our modeling. This computer-intensive approach to experiment design is a legacy of our practice in underground nuclear tests and helps to ensure a good return on the dollars spent in these experiments.

Test warheads contain no actual nuclear materials, but in other important respects warheads and projectiles alike 


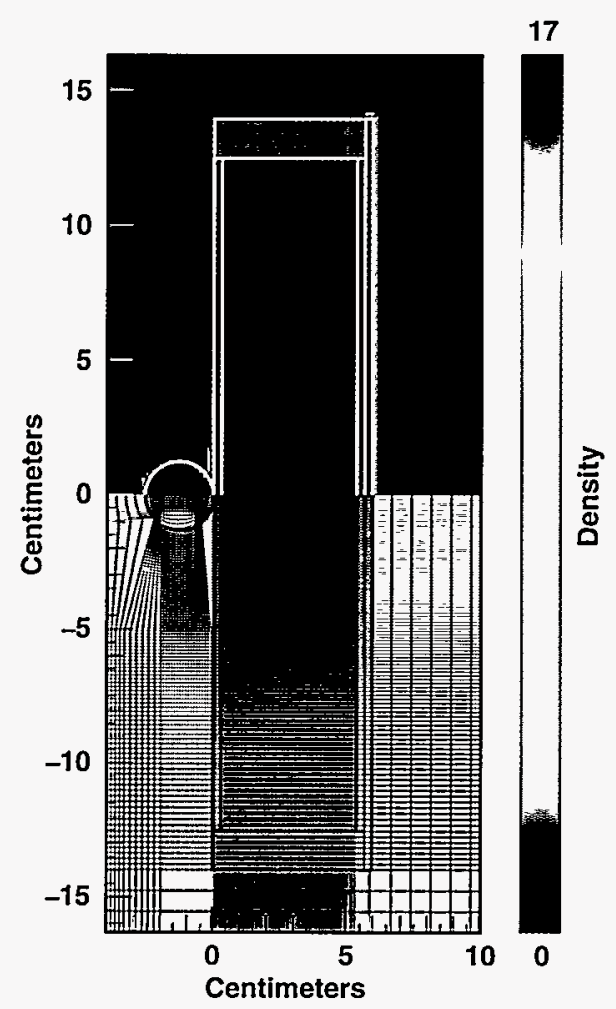

Top of figure shows the initial configuration of a 25-mm tungsten sphere impacting the HE target. Colors indicate different material densities. Below is the CALE geometry setup for numerical analysis showing typical zoning used and the material boundaries.

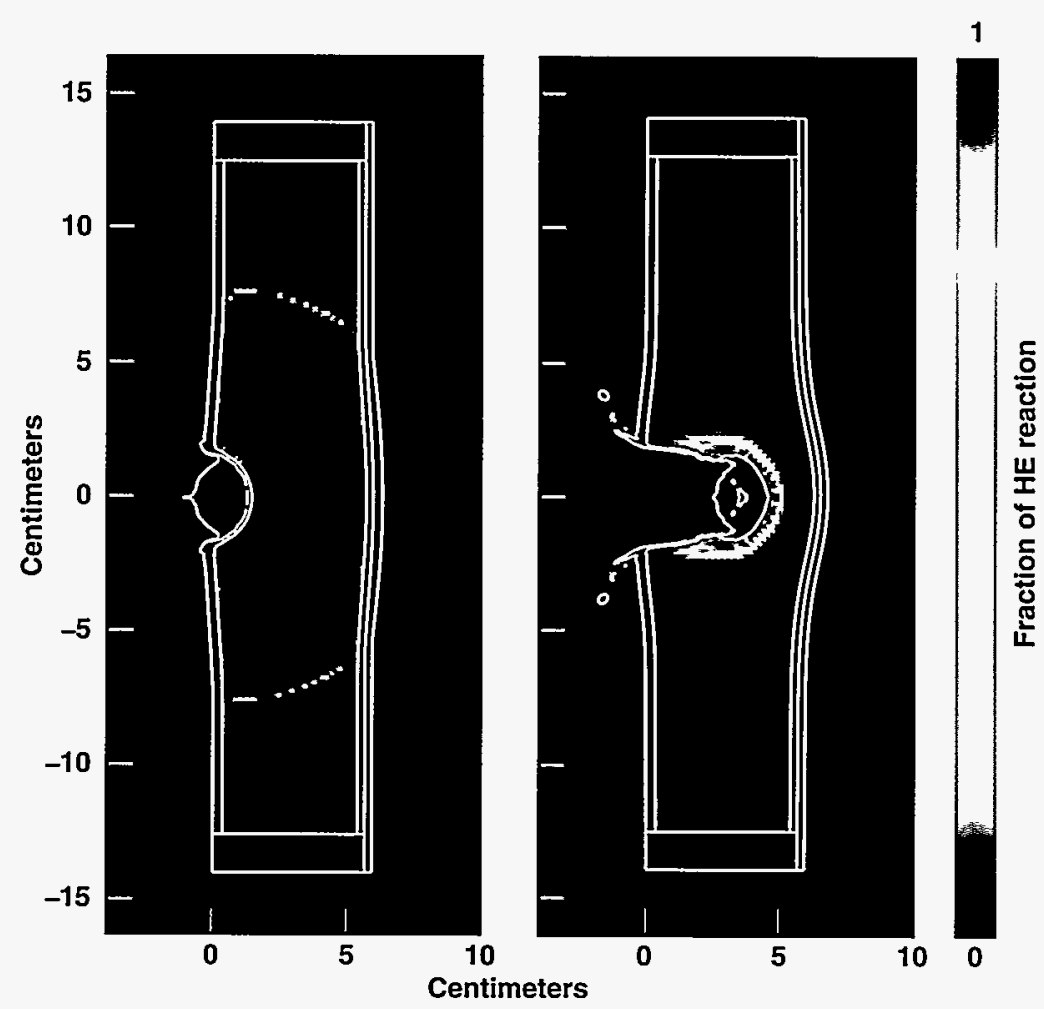

(Left) Prompt detonation of the HE is shown by the fraction of HE reacted after $18 \mu \mathrm{s}$ for the projectile velocity of $1.3 \mathrm{~km} / \mathrm{s}$. Red color indicates fully reacted HE, while blues indicate no reaction. (Right) Low-level reaction in the HE is shown by the small amount of material reacted (essentially no red region), for a projectile velocity of only $1.06 \mathrm{~km} / \mathrm{s}$. are designed to accurately represent real-world systems. This is true whether the models are full scale or are scaled down, as is often the case, because the projectiles must be small enough to be fired by a light gas gun. The models have mock components made of materials that replicate (within their scale) the weight, strength, and other properties of materials in actual warheads and in prospective interceptor designs. The models therefore have the same total or scaled weight and distribution of weight as their counterparts. The figure on the opposite page shows a simulation of a $\mathrm{KE}$ interceptor striking a nuclear-tipped tactical missile.

The responses of the materials used in our tests vary greatly over the range of test velocities. The relative velocity (or closing rate) of a $\mathrm{KE}$ intercept may vary from a low of 1 to $2 \mathrm{~km} / \mathrm{s}$ up to a hypervelocity of 8 to $10 \mathrm{~km} / \mathrm{s}$ $(10 \mathrm{~km} / \mathrm{s}=36,000 \mathrm{~km} / \mathrm{hr})$.

\section{Proving Our Codes}

Because only a finite number of tests can be conducted, they must serve dual purposes. They give the experimental results of striking a given target with a given projectile and also provide data with which to refine our codes. As these codes become progressively more refined, they more reliably describe the impacts of simulated projectiles on simulated targets (see above figures). Eventually, the codes should enable us to "test" (within the computer) any combination of warhead and interceptor designs in simulated conditions of the group's choosing. Actual experiments will simply confirm the reliability of the codes.

We are evaluating two lethal mechanisms for killing nuclear warheads: destruction of the high explosives in the warhead, and breakup of the warhead into many fragments.

Both methods eliminate the possibility of nuclear yield, the first by eliminating the trigger for nuclear ignition, the second by eliminating the requisite critical mass for a chain reaction even in the presence of an explosion-as long as the warhead's contact (or salvage) fuze is not armed. Otherwise, the impact of the kinetic energy interceptor is likely to trigger a full-yield nuclear explosion. Only a nuclear interceptor with a yield of a small fraction of a kiloton is sufficient to defeat a fuzed and armed nuclear target.

Actual experiments (figures above) conducted with identical parameters to such simulations are conducted at various two-stage light gas gun facilities. The test results, 


Comparison of the
CALE calculations for
the Composition-B HE
initiation with the
results of experiments
at the Naval Research
Laboratory, showing
the range between
detonation and
nondetonation. The
calculations show
excellent agreement
with the test results.
Calculated
Composition-B
density was 1.7 g/cm ${ }^{3}$;
tested density was
1.63 g/cm ${ }^{3}$.

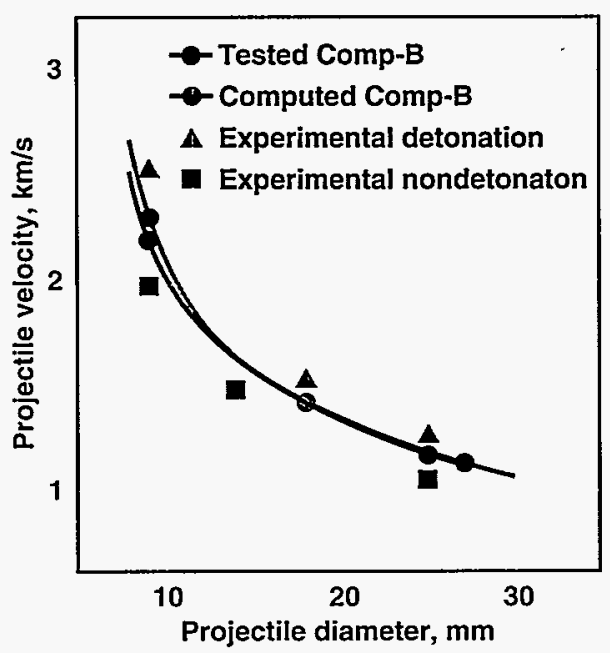

together with 2D and 3D hydrodynamic code analyses, are used to interpret the tests and establish the lethality of the $\mathrm{KE}$ interceptor. One of the codes used extensively for analyses of the intercepts is CALE (an Arbitrary Lagrangian Eulerian code written in the language C), ${ }^{1}$ which implements our ignition and growth reactive flow model. ${ }^{2}$ CALE enables us to calculate how most types of high explosive (HE) of interest for application in counterproliferation respond when impacted by a $\mathrm{KE}$ projectile of given properties. The mesh in the figure on top left of page 23 shows the CALE setup geometry for numerical analysis of a projectile impacting an $\mathrm{HE}$ target and the density of a $25-\mathrm{mm}$ tungsten spherical projectile impacting the HE target. The HE figure shows the results of impacts at two relative velocities: at $1.3 \mathrm{~km} / \mathrm{s}$, the impact produces a prompt detonation at $15 \mu \mathrm{s}$ in the $\mathrm{HE}$; at $1.06 \mathrm{~km} / \mathrm{s}$, the projectile penetrates into the $\mathrm{HE}$, but at $60 \mu$ s has only produced a low-level reaction. The graph (at left) shows a comparison of our analysis with experimental results for Composition-B HE, our benchmark HE used in studies of our ignition growth model. Simulations run on our $2 \mathrm{D}$ and $3 \mathrm{D}$ codes have shown excellent agreement with experimental results, giving us confidence in their ability to reliably expand the range of test parameters.

\section{Projected Work}

For the purpose of studying the effectiveness of warhead interceptors, we have simulated a simple nuclear warhead concept that we believe represents what aggressively proliferant nations might devise. We have built a generic model target for lethality testing and conducted two half-scale tests. We are now building fullscale targets for testing on a sled track at Holliman Air Force Base in New Mexico, where an actual interceptor vehicle will be fired into a target. We will evaluate the lethality of the systems being fielded against this target.

References

1. R. Tipton, CALE User's Manual, Version 101491, Lawrence Livermore National Laboratory, Livermore, CA, 94550 (1991).

2. E. L. Lee and C. M. Tarver, "Phenomenological Model of Shock Initiation in Heterogeneous Explosives," Phys. Fluids 23 (12), December 1980, pp. 2362-2372.

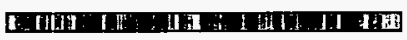

For further information contact Glenn W. Pomykal (510) 422-4728,gwp@llnl.gov. 


\section{New Patents Issued to Laboratory Inventors}

\section{Inventors \\ Patent Name, Number, and Date Issued}

Method for Continuously Recovering Metals Using

a Dual Zone Chemical Reactor

U.S. Patent 5,389,123

February 14, 1995
The continuous processing of metal-containing compounds in a single, dual zone reactor that contains a recycling, regenerated liquid carrier. The reactor continuously recovers metals from a feedstock of metal oxides or salts.
Daniel M. Makowiecki Magnetron Sputtered Boron Films and Ti/B Alan F. Jankowski Multilayer Structures

U.S. Patent 5,389,445

February 14, 1995
A low-atomic-number/high-atomic-number multilayer structure comprising a thin, amorphous, boron layer having no morphological growth features as the lowatomic-number layer, and a transition metal layer as the high-atomic-number layer.

A process for fabricating high-density-boron sputtering targets with sufficient chemical strength to function reliably at typical magnetron sputtering power densities and at normal process parameters.
Peter B. Mohr Double-Ended Ceramic Helical-Rotor Expander Wendell B. Myers

U.S. Patent 5,393,209

February 28, 1995

Cell Separator for Use in Bipolar-Stack Energy Storage Devices

U.S. Patent 5,393,619

February 28, 1995
A ceramic helical rotor expander using a double-ended or tandem herringbone-type rotor arrangement with bearing and seal assemblies remote from the hot-gas inlets and especially capable of operating at an inlet temperature of above $1100^{\circ} \mathrm{C}$.
Steven T. Mayer

John H. Feikert

James L. Kaschmitter

Richard W. Pekala
U.S. Patent 5,392,981

February 28, 1995
An improved, multicell, electrochemical energystorage device using a cell separator hat that allows cells to be stacked and interconnected with low electrical resistance and high reliability while maximizing packaging efficiency. 


\section{Creating Microsphere Targets for Inertial Confinement Fusion Experiments}

The targets used in inertial confinement fusion (ICF) experiments at the Lawrence Livermore National Laboratory are plastic capsules roughly half a millimeter in diameter. This article reviews the fabrication of these capsules, focusing on the production of the thin-walled polystyrene microshell around which the capsule is built. The relationship between the capsule characteristics, especially surface finish, and capsule performance is discussed, as are the methods of surface characterization and modification necessary for experiments designed to study the effects of surface roughness on implosion dynamics. Targets for the next generation of ICF facilities using more powerful laser drivers will have to be larger while meeting the same or even more stringent symmetry and surface finish requirements. Some of the technologies for meeting these needs are discussed briefly.

Contact: Robert Cook (510) 422-3117.

\section{$E \& T R$ Celebrates 20 Years}

Energy and Technology Review celebrates its 20th Anniversary in this April 1995 issue of the publication. With quotes from influential contributors, the article highlights the publication's changes in focus, wide coverage of Laboratory science, experiences of scientific editors, and graphic design changes over the years. Also in the article are the whereabouts of past scientific editors and a statement by Laboratory Director C. Bruce Tarter. 